\title{
Downscaling GRACE Predictions of the Crustal Response to the Present-day Mass Changes in Greenland
}

Wang, Linsong; Khan, Shfaqat A.; Bevis, Michael; van den Broeke, Michiel R.; Kaban, Mikhail K.; Thomas, Maik; Chen, Chao

Published in:

Journal of Geophysical Research: Solid Earth

Link to article, DOI:

10.1029/2018JB016883

Publication date:

2019

Document Version

Peer reviewed version

Link back to DTU Orbit

Citation (APA):

Wang, L., Khan, S. A., Bevis, M., van den Broeke, M. R., Kaban, M. K., Thomas, M., \& Chen, C. (2019). Downscaling GRACE Predictions of the Crustal Response to the Present-day Mass Changes in Greenland. Journal of Geophysical Research: Solid Earth, 124(5), 5134-5152. https://doi.org/10.1029/2018JB016883

\section{General rights}

Copyright and moral rights for the publications made accessible in the public portal are retained by the authors and/or other copyright owners and it is a condition of accessing publications that users recognise and abide by the legal requirements associated with these rights.

- Users may download and print one copy of any publication from the public portal for the purpose of private study or research.

- You may not further distribute the material or use it for any profit-making activity or commercial gain

- You may freely distribute the URL identifying the publication in the public portal 
Wang Linsong (Orcid ID: 0000-0002-3980-479X)

Khan Shfaqat, Abbas (Orcid ID: 0000-0002-2689-8563)

Bevis Michael, G. (Orcid ID: 0000-0002-4944-8186)

van den Broeke Michiel, R. (Orcid ID: 0000-0003-4662-7565)

Kaban Mikhail, K (Orcid ID: 0000-0002-1864-2234)

Chen Chao (Orcid ID: 0000-0001-5021-788X)

\section{Downscaling GRACE Predictions of the Crustal Response to the Present-day Mass Changes in Greenland}

\section{Linsong Wang ${ }^{1,2}$, Shfaqat A. Khan ${ }^{3,}$ Michael Bevis ${ }^{4}$, Michiel R. van den Broeke ${ }^{5}$, Mikhail K. Kaban ${ }^{2}$, Maik Thomas ${ }^{2,6}$ and Chao Chen ${ }^{1}$}

${ }^{1}$ Hubei Subsurface Multi-scale Imaging Key Laboratory, Institute of Geophysics and Geomatics, China University of Geosciences, Wuhan, China.

${ }^{2}$ Helmholtz Centre Potsdam, GFZ German Research Centre for Geosciences, Telegrafenberg, Potsdam, Germany.

${ }^{3}$ DTU Space-National Space Institute, Technical University of Denmark, Kongens Lyngby, Denmark.

${ }^{4}$ School of Earth Sciences, Ohio State University, Columbus, Ohio, USA.

${ }^{5}$ Institute for Marine and Atmospheric Research Utrecht, Utrecht University, Utrecht, Netherlands.

${ }^{6}$ Institute of Meteorology, Freie Universität Berlin, Berlin, Germany.

Corresponding author: Linsong Wang (wanglinsong@cug.edu.cn)

\section{Key Points:}

- GRACE results can be improved by using scaling factors estimated from two models of surface mass fields in Greenland

- Scaled GRACE-derived and GPS-observed vertical displacements were compared at 53 Greenland GPS Network (GNET) stations

- GRACE-based estimates of accurate uplift rates in Greenland needs to consider the spatial pattern of ice loss and reliable GIA correction

This article has been accepted for publication and undergone full peer review but has not been through the copyediting, typesetting, pagination and proofreading process which may lead to differences between this version and the Version of Record. Please cite this article as doi: 10.1029/2018JB016883

(c) 2019 American Geophysical Union. All rights reserved. 


\begin{abstract}
The GRACE mission has had a revolutionary impact on the study of Earth system processes, but it provides a band-limited representation of mass changes. This is particularly problematic when studying mass changes that tend to be concentrated in fairly narrow zones near the edges of the Greenland Ice Sheet (GrIS). In this study, coarse-resolution estimates of the mass change derived from GRACE have been enhanced by the introduction of heuristic scaling factors applied to model surface mass balance (SMB) and observed surface elevation change (SEC). Corresponding results indicate large spatial heterogeneity in the gridded scaling factors at the $0.5^{\circ} \times 0.5^{\circ}$ scale, reflecting significant mass losses concentrated along the ice sheet margin and relatively small internal ice sheet changes at higher elevations. The scaled GRACE-derived vertical displacements are in the range from -2 to $14 \mathrm{~mm} / \mathrm{yr}$ from 2003 to 2015. The Greenland GPS network (GNET) was used to examine the downscaling GRACE predictions of the crustal displacements. The results show consistency of scaled GRACE-predicted and GPS-observed seasonal and long-term uplift in major drainage basins of Greenland. Our results indicate that GRACE predictions underestimate vertical displacements at sites located in regions characterized by concentrated loads, but perform well in other regions. Differences between predicted and observed uplift rates are mainly caused by the sensitivity kernels, because GPS and GRACE estimates are based on weighted averages of mass loss in different sensitivity ranges. Moreover, a large uncertainty in the glacial isostatic adjustment (GIA) correction may also cause errors in the GPS-to-GRACE ratio.
\end{abstract}

\title{
1 Introduction
}

In the last 15 years, the Greenland Ice Sheet (GrIS) has lost more ice than the far larger Antarctic Ice Sheet. If completely melted, the GrIS would raise sea level by 7 meters, therefore it is important to understand the extent to which the ice loss has accelerated at decadal time scales (Chen et al., 2017; Bevis et al., 2019), and whether those trends will continue. Making accurate predictions about future ice loss requires a deeper understanding of its multiple causes. This motivates us to monitor both the spatial and temporal patterns of mass loss at the highest resolution possible. Estimates of the mass change of the GrIS have improved in recent years with growing sets of satellite observations- especially gravity field changes from GRACE (Jacob et al., 2012; Velicogna et al., 2014) and elevation changes from ICESat (Ice, Cloud, and land Elevation Satellite) missions (Shepherd et al., 2012; Zwally et al., 2011; Gardner et al., 2013). It is also possible to evaluate ice loss by measuring the elastic response of Earth's crust to mass change using field GPS observations (Farrell, 1972).

However, reliable estimates can only be made by combining all relevant observations, so that the strengths of each method can compensate for the weaknesses in others. This work explores such a multisensor, multiphysics approach.

Since 2007, the Greenland GPS Network (GNET) has been used to constrain past (Last Glacial Maximum) and present-day changes in the mass balance of the GrIS. GNET utilizes more than 50 continuous GPS stations to measure displacements of the bedrock exposed near the margins of the GrIS. Previous publications indicate that the entire area is uplifting, mainly due to glacial isostatic adjustment (GIA) - i.e. the delayed viscoelastic response to past changes in ice mass - and the instantaneous elastic response to present-day ice mass changes (Bevis et al., 2012; Khan et al., 2010, 2016; Liu et al., 2017; Wang et al., 2018).

Surface mass redistribution is mainly controlled by changes in terrestrial water storage in its various forms (liquid, snow, firn, and ice) and by variations in atmospheric 
pressure and ocean transports on different timescales (from daily to annual) (Kusche and Schrama, 2005). The contribution of the atmospheric pressure changes and ocean mass redistribution can be reasonably well modelled using global in-situ and space geodetic data. Thus, after removing these effects, e.g., using the atmospheric and oceanic mass variation models such as Atmosphere and Ocean De-aliasing Level-1B (AOD1B) products, the surface mass changes derived from GRACE and GPS data can determine changes in other systems, such as hydrological storage systems. However, it is misleading to directly compare GRACE estimates with GPS observations, because (1) GPS measurements are more sensitive to mass loads in the vicinity of the sites than to the loads located hundreds of kilometers away (Bevis et al., 2005; Khan et al., 2010), and (2) GRACE data with a spatial resolution of $\sim 330 \mathrm{~km}$ reflects these variations at a monthly time scale, and thus provides a band-limited representation of near-surface mass changes. When combining GRACE and GPS data to infer tectonic movement or contemporary rates of GIA in Greenland, GRACE underestimates Greenland vertical displacements at sites very close to regions of concentrated loads, but it is will be place with overestimation at sites far away load region due to smoothing effect of a few hundred kilometers radius in the post-processing of GRACE data. When using GRACE to remove surface mass contributions from GPS observations (particularly the effects of ongoing Greenland mass loss), GRACE-based results of crustal displacements require confidence that there is no concentrated load signal very close the GPS site. GRACE data would therefore need to be adjusted by using downscaling factors estimated from a realistic mass loss patterns to restore the lost signal.

The scaling factor approach consists of gain factors for specific regions derived by a least square fit between filtered and unfiltered modeled outputs described by Landerer and Swenson, (2012). It is widely used to restore GRACE-derived terrestrial water storage (TWS) change signals, especially in recent gridded GRACE TWS anomaly products (Sun, 2013; Long et al., 2015; Zhang et al., 2016). In this study, we focus on the ability of GRACE to estimate accurate secular trends for vertical crustal displacements in response to the presentday mass loss from GrIS. We first present the relationship between uplift and surface mass change at different scales, in which the degree of the loading Green's function is truncated to different upper limits. Next, two gridded surface mass models were used, the surface mass balance (SMB) and the surface elevation change (SEC), to construct a spatial distribution of the scaling factors to adjust GRACE estimates. Data from 53 GNET sites was used to compare GPS-observed uplifts (corrected for atmospheric and non-tidal oceanic loading and the GIA effects) with scaled GRACE predictions in Greenland for the GNET locations (Figure 1a). Furthermore, we discuss the sensitivity of the scaling factors to the model used as well as to other corrections, such as different sensitivities of GPS and GRACE data to mass loading and the uncertainty of the GIA correction.

\section{Theory, Data and Methods}

\subsection{Relationship between bedrock uplift and ice mass change}

A GRACE gravity model is provided below in terms of numerical values of the Stokes coefficients $C_{l m}$ and $S_{l m}$. A procedure to transfer these coefficients to changes in the surface mass load is described by Wahr et al. (1998). The changes $\Delta C_{l m}$ and $\Delta S_{l m}$ in the geoid coefficients as provided by GRACE gravity field solutions are widely used to estimate corresponding variations in surface mass or equivalent water thickness (EWT) $\Delta \sigma(\theta, \phi)$ :

$$
\Delta \sigma(\theta, \phi)=\frac{a \rho_{a v e}}{3} \sum_{l}^{\infty} \sum_{m=0}^{l} \tilde{P}_{l m}(\cos \theta) \frac{2 l+1}{1+k_{l}}\left(\Delta C_{l m} \cos (m \phi)+\Delta S_{l m} \sin (m \phi)\right)
$$


where $\theta$ and $\phi$ are longitude and colatitude, $\rho_{\text {ave }}$ is the mean water density, $a=6371 \mathrm{~km}$ is the mean radius of the Earth, and $\tilde{P}_{l m}$ are fully normalized Legendre functions of degree $l$ and order $m$.

According to the elastic loading theory described by Farrell (1972), the GRACE Stokes coefficients and load Love numbers $\left(h_{l}, k_{l}\right.$ and $\left.l_{l}\right)$ can be used to estimate surface displacements (vertical, north, and east) induced by surface mass loading. The relationship between the vertical component and the Stokes mass coefficients is suggested in (van Dam et al., 2007; Kusche and Schrama, 2005):

$\Delta h=S_{r}(\theta, \phi)=a \sum_{l}^{\infty} \sum_{m=0}^{l} \tilde{P}_{l m}(\cos \theta) \frac{h_{l}}{1+k_{l}}\left(\Delta C_{l m} \cos (m \phi)+\Delta S_{l m} \sin (m \phi)\right)$

Relating $\Delta C_{l m}, \Delta S_{l m}$ to the surface mass distribution $\Delta \sigma(\theta, \phi)$ :

$\left\{\begin{array}{l}\Delta C_{l m} \\ \Delta S_{l m}\end{array}\right\}=\frac{3\left(1+k_{l}\right)}{4 \pi a \rho_{a v e}(2 l+1)} \int_{\text {earth }} \Delta \sigma(\theta, \phi) \tilde{P}_{l m}(\cos \theta)\left\{\begin{array}{l}\cos (m \phi) \\ \sin (m \phi)\end{array}\right\} \sin \theta d \theta d \phi$

Combining (3) with (2) gives:

$S_{r}(\theta, \phi)=\int_{e a r t h} G_{r}\left(\theta, \phi ; \theta^{\prime}, \phi^{\prime}\right) \Delta \sigma\left(\theta^{\prime}, \phi^{\prime}\right) a^{2} \sin \theta^{\prime} d \theta^{\prime} d \phi^{\prime}$

where Green's function (for uplift) is:

$G_{r}\left(\theta, \phi ; \theta^{\prime}, \phi^{\prime}\right)=\sum_{l}^{\infty} \frac{3 h_{l}}{4 \pi a^{2} \rho_{a v e}} \widetilde{P}_{l}(\cos \alpha)$

Here, $\alpha$ is the geocentric angle between $(\theta, \phi)$ and $\left(\theta^{\prime}, \phi^{\prime}\right)$. Because GRACE delivers $\Delta C_{l m}, \Delta S_{l m}$ only up to $l_{\max }=60$, computing $S_{r}$ using (2) is equivalent to using a Green's function, in which the upper limit of sum $l_{\max }=60$.

2.2 Surface mass changes from GRACE, SMB, and SEC data

Earth's gravity field changes acquired by GRACE are particularly useful for monitoring surface mass changes at large-scales (Tapley et al., 2004). In this study, we used monthly sets of the Stokes coefficients from the GRACE Release-05 (RL05) Level-2 solutions provided by the Center for Space Research (CSR) at the University of Texas, spanning January 2003 to December 2015. These solutions have a resolution up to degree and order $(l$ and $m)$ 60. The $C_{20}$ coefficient, which is related to flattening of the Earth, is replaced by one estimated from satellite laser ranging data (Cheng et al., 2013). Because the global gravity field is typically calculated in the Earth's center of mass (CM) reference frame, the Degree-1 variations (geocenter motion) are not presented in the GRACE solutions. Here, we used the Degree-1 coefficients derived by Swenson et al. (2008) to determine the position of the CM relative to the center of figure (CF) frame of the Earth's outer surface. Gaussian smoothing with an averaging radius of $200 \mathrm{~km}$ was applied to suppress errors in high degree coefficients (Wahr et al., 1998; van Dam et al., 2007). The contributions from GIA were modeled using the Stokes coefficients estimated by A et al. (2013), which were based on the ICE-5G global ice loading history. Figure $1 \mathrm{~b}$ shows the long-term mass trends for Greenland obtained from the monthly GRACE solutions (after the processing described above) for the period 2003 to 2015 .

The main purpose of this study was to downscale GRACE predictions of crustal displacements in response to the surface mass variability in Greenland. Thus, two surface mass models were used to compare GRACE-derived mass changes and further model the loading elastic responses. One of the synthetic models was the gridded SMB product from the Regional Atmospheric Climate Model 2.3 (RACMO2.3), providing monthly SMB with a $\sim 11 \times 11 \mathrm{~km}^{2}$ spatial resolution for January 1958 to December 2015 (Noël et al., 2016). 
Because ice loss caused by glacier acceleration was not included in the SMB model as well as large runoff due to surface mass fluxes at the boundary of the ice sheet (i.e., meltwater and snowfalls), the current version of RACMO2.3 was insufficient to resolve individual, lowlying outlet glaciers of the ice sheets (Noël et al., 2018). This leads to potentially large errors in local SMB values. The second synthetic model used the SEC gridded data from satellite altimetry. The SEC includes crustal motion, ice thickness changes, and changes in firn layer thickness. Surface elevation changes can be used to isolate the dynamical ice contributions to the mass loss. We first removed the effects of disconnected ice caps in Greenland using the ice sheet mask from RACMO2.3. The temporal average of the accumulation rates was then removed at each grid point, and temporal anomalies were integrated to obtain gridded SMB values covering the same time period as the GRACE data. The fitting trend of the monthly accumulated SMB variations from January 2003 to December 2015 is shown in Figure 1c. We used the merged SEC data from ICESat from 2003 to 2009 (Zwally et al., 2014) and CryoSat-2 during 2010-2015 (Simonsen and Sørensen, 2017) missions to estimate ice elevation changes at a spatial resolution of $\sim 5 \times 5 \mathrm{~km}^{2}$, converting volume loss rates to mass loss rates, and assuming a uniform ice density $\left(917 \mathrm{~kg} / \mathrm{m}^{3}\right)$ without considering compaction effects (Figure 1d). Finally, the SMB and SEC gridded data were converted to the Stokes coefficients and truncated to degree 60 to be consistent with GRACE data limits.

\subsection{Crustal displacements from GNET data}

In total, 53 GPS sites from GNET (Figure 1a) were analyzed in this study (see Table S2 in Supporting Information for details). Vertical crustal displacements usually represent a superposition of annual oscillations, interannual variations, and a sustained trend (Bevis et al., 2012). We used conventional methods described by Khan et al. $(2008 ; 2010)$ to process the GNET data. For example, GIPSY/OASIS-II (Version 5.0) software was used to compute the point positioning mode to obtain the daily coordinates and covariances; these were then used to transform the daily values into the International Terrestrial Reference Frame 2008 (ITRF2008, Altamimi et al., 2012), which is in the center of surface figure (CF) at annual time scales (Dong et al., 2003). International Earth Rotation and Reference Systems (IERS) 2010 conventions was applied to correct the solid-Earth tides and pole tides, and ocean tide loading effects were corrected using ocean tide model FES2004 with Greens Functions modeled in the reference frame of CM (Lyard et al., 2006). This provides consistency with the current IERS conventions (Fu et al., 2012; Hao et al., 2016).

In our processing strategy, the AOD1B product was not added back into the GRACE Stokes coefficients, which means that GRACE-derived loading deformations did not include atmospheric and non-tidal ocean effects. To remove these loading effects on the GPS coordinates, we computed the displacements due to atmospheric loading using data and programs provided by the Global Geophysical Fluid Center (van Dam, 2010), which utilizes the surface pressure data from the National Center of Environmental Protection (NCEP). The 12-hour sampling model, Estimating the Circulation \& Climate of the Ocean (ECCO), was used to compute the surface displacements due to non-tidal ocean effects with a spatial resolution $1^{\circ} \times 0.3-1.0^{\circ}$. We removed GIA effects for all GPS stations by applying the "GNET-GIA" results of Khan et al. (2016), which are based on satellite radar/laser altimetry observations used to model and remove the Earth's crust elastic response at GNET sites.

Finally, we generated monthly vertical GPS solutions using the weighted average method and monthly time span of GRACE epoch:

$$
\mathrm{GPS}_{\text {monthly }}=\sum_{i=1}^{N} \frac{\operatorname{GPS}(i)}{\operatorname{sigma}(i)^{2}} / \sum_{i=1}^{N} \frac{1}{\operatorname{sigma}(i)^{2}}
$$


Here, $\mathrm{N}$ are the days of monthly GRACE epoch, and sigma $(i)$ is the formal error of the $i$ th day. We also fitted the height component of the displacement (U) at each GPS station to obtain the secular trend and annual oscillations (uplift rates are shown in Figure 2) based on fitting harmonic functions (sines and cosines) to the data using least-squares method with a 6 months half-width moving window (the same fitting method to process the GRACEbased results).

\subsection{Scaling factors of ice mass and vertical displacement}

For the scaling factors to restore GRACE-based mass changes, most of the early studies applied downscaling methods involving scaling factors (e.g., Landerer and Swenson, 2012; Long et al., 2015; and others) that were derived by gridded land surface model (LSM) outputs with the same processing as in GRACE to calculate gridded-gain factors at each grid point. Following Landerer and Swenson (2012), we generated gridded scaling factors of GrIS mass change using forward modeling and surface mass fields. Because the SMB and the SEC coefficients after truncation and filtering were remapped to the $0.5^{\circ} \times 0.5^{\circ}$ grids to quantify the signal attenuation, yet the original two surface mass models were not standard latitude/longitude grids (SMB with a $\sim 11 \mathrm{~km} \times 11 \mathrm{~km}$ spatial resolution and SEC with a $\sim 5$ $\mathrm{km} \times 5 \mathrm{~km}$ spatial resolution), the original model data were re-sampled to $0.5^{\circ} \times 0.5^{\circ}$ grids using a central moving average and root-mean-square (RMS) error to calculate the weighted mean values at each grid. The weighted averaging method is similar to the process of generated GPS monthly data (equation-6), but $\mathrm{N}$ is the total number of original model data at each $0.5^{\circ}$ grid. An example of data resampling is shown in Figure S1; a GrIS mask at $0.5^{\circ} \times$ $0.5^{\circ}$ resolution was used to constrain the spatial distribution of ice sheets (e.g., to exclude exposed rock or floating ice), and this was then re-sampled at $0.5^{\circ} \times 0.5^{\circ}$ resolution and taken as the reference relative to which the truncation and filtering effects were evaluated.

As described in Section 2.2, the two surface mass fields (the monthly SMB anomalies and the yearly SEC changes) have different observed physical parameters and RMS distributions at each $0.5^{\circ}$ girds. SMB represents the sum of mass fluxes inside and away from ice sheets yet SEC reflects changes in ice sheet elevation and volume. Thus, we adopted a weighted average processing method to generate the final weighted scaling factors, including a simple least squares regression described by Landerer and Swenson (2012) in order to fit SMB and SEC model separately to obtain two sets of scaling factors ( $s f_{S M B}$ and $\left.s f_{S E C}\right)$ and two RMS errors scaling factors ( $s f_{S M B_{-} \text {error }}$ and $\left.s f_{S E C_{-} \text {error }}\right)$. The scaling factor for error was used to calculate the weight of the final results:

$$
\text { weighted average scaling factors }(\mathrm{sf})=\frac{s f_{S E C} / s f_{S E C_{\text {_error }}}^{2}+s f_{S M B} / s f_{S M B_{e} e r r o r}^{2}}{1 / s f_{S E C_{-} e r r o r}^{2}+1 / s f_{S M B_{-} \text {error }}^{2}}
$$

In this process, each model to be averaged was assigned a weight that determined the relative importance of this model. The RMS error of SEC and SMB and its scaling factors and weights for ice mass are shown in Figure S2. The weighted scaling factors can better reflect the contribution of the two models within each grid cell. For example, a larger $s f_{S M B_{-} \text {error }}$ will increase the uncertainty of $s f_{S M B}$ and the weight of the contribution of $s f_{S M B}$ to the final result will then be less than $s f_{S E C}$. Finally, the gridded weighted scaling factors from SMB and SEC were applied to the corresponding filtered GRACE-based mass change for each grid cell within the GrIS, and then the rescaled mass change for all grid cells were spatially averaged to obtain the total GrIS mass change.

The difference between the scaling factors for displacement and scaling factors for mass is that the SMB- or SEC-derived displacement needs to be combined with the load Love number (e.g., equation-2) or load Green's function (e.g., equation-4). Ideally, when those 
scaling factors are applied to the GRACE filtered data $\left(l_{\max }=60\right)$, the restored GRACEderived displacement will be close to the in-situ geodetic GPS data. The scaling factors for displacement (i.e., predicted GPS-to-GRACE ratios) derived from SMB and SEC outputs can then be assessed using observed GPS-to-GRACE ratios. The estimated linear trends derived from GPS (red arrows) and GRACE (grey arrows) data are shown in Figure 2. In many sites, the GRACE-derived uplift rates are less than those observed because GPS measurements are sensitive to load changes in the vicinity of each site combined with remote loads, whereas the GRACE solution is truncated to $l_{\max }=60$, therefore concentrated loads are smoothed. This difference reflects $l_{\max }=60, l_{\max }=180$ and $l_{\max }=\infty$ for spherical harmonic coefficient truncations and vertical Green's function change for different upper limits of $l_{\max }$ within $2,000 \mathrm{~km}$, as shown in Figure S3. Therefore, the GPS-to-GRACE ratios depend on the spatial distribution of the ice loss and sensitivity to GIA.

We estimated the scaling factors at each grid point, which relate the model-predicted deformations and the prediction after spherical harmonic truncation and spatial filtering. A flow-chart for the derivation of scaling factors to adjust the GRACE-derived vertical displacement is given in Figure S4; this procedure included the following steps:

(1) Forward modeling (SMB and SEC) mimics low-pass filtering (truncation and Gaussian filtering) for GRACE solutions, followed by a calculation of the vertical displacements $\left(\mathrm{SMB} / \mathrm{SEC}_{\mathrm{Up} \_60}\right)$ on a $0.5^{\circ} \times 0.5^{\circ}$ grid using equation-2 and the load Love numbers (Han and Wahr, 1995). In this step, the vertical displacements due to the RMS error corresponding to the two models were also calculated.

(2) The gridded mass loss estimates from SMB and SEC were convolved with the Green's function computed according to Jentzsch (1997) for PREM (Dziewonski and Anderson, 1981) to predict vertical displacements, which also included the displacement caused by the RMS error, at the $0.5^{\circ} \times 0.5^{\circ}$ scale $\left(\mathrm{SMB} / \mathrm{SEC}_{\mathrm{Up}_{-} \infty}\right)$.

(3) The weighted average of gridded scaling factors of the vertical displacement response to present-day mass change in Greenland at $0.5^{\circ} \times 0.5^{\circ}$ scale were also generated using the prediction results from equation-(1), -(2), and -(7).

(4) The GRACE prediction of vertical displacements $\left(\mathrm{GRACE}_{\mathrm{Up}_{-} 60}\right)$ were then rescaled based on the weighted gridded scaling factors (the RMS error of SEC and SMB and its scaling factors and weights for crustal uplift are shown in Figure S5) to obtain the restored $\mathrm{GRACE}_{\mathrm{Up} \_\infty}$ at $0.5^{\circ} \times 0.5^{\circ}$ gridding.

In order to evaluate GRACE-derived vertical displacements, we also constructed the scaling factors at the GNET GPS sites using steps (1) to (4), and then compared the scaled GRACE predictions of vertical motion with the corrected GPS solutions.

\section{Results}

3.1 Scaled GRACE GrIS mass change estimates

The GRACE results might be improved by using scaling factors estimated from a realistic mass loss pattern. Conversely, the confidence of synthetic models of mass change in Greenland has improved through comparison with GRACE data (van den Broeke et al., 2016; Sasgen et al., 2012; Velicogna et al., 2014). Truncating, filtering, and smoothing GRACE data lead to differences between basin-averaged ice mass changes and GPS based values due to the attenuation of highly localized signals, and the increase of spatial leakage of the signals from neighboring regions (Werth et al., 2009). 
To ensure that the model simulations were similar to the physical process of the ice mass change, we selected two surface mass models to estimate the weighted scaling factors to reduce the bias and leakage effects from GRACE data. The reasoning for not choosing just one signal is two-fold. First, a $\sim 11 \mathrm{~km}$ grid of SMB is sufficient to resolve large-scale inland surface mass balance patterns, but it does not adequately resolve irregular, low-lying regions at the GrIS margins, where run-off peaks due to total run-off of meltwater from the narrow ablation zone and small outlet glaciers (Noël et al., 2018). Thus, SMB is likely to underestimate the loss of actual GrIS mass, especially along the edges of GrIS. Second, SEC can successfully resolve changes in ice sheet elevation and volume at a high spatial $(5 \mathrm{~km})$ resolution, but there is still a large uncertainty in the estimate of the density of the material lost or gained. This variation in material volume is dependent upon the timescale of the perturbation and the proportion of the thickness change occurring within the firn and underlying ice column (McMillan et al., 2016). Previous studies used two approaches for converting elevation change to mass balance: the predefined density model and firn compaction corrections (McMillan et al., 2016; Li and Zwally, 2011). The predefined density model uses an ice density of $917 \mathrm{~kg} / \mathrm{m}^{3}$ in the high rates of elevation change and ice flow (i.e., the GrIS margins) and uses a mean density of the modelled firn layers in other regions (i.e., high altitude area). This approach relies on the ability of existing data sets to establish a major area that exhibits dynamic imbalances. The firn compaction model requires a high level of accuracy for both the observed ice thickness and modelled firn thickness across the entire ice sheet. The errors in the observed and modelled elevation will affect the final estimate of ice sheet mass change.

In this study, we used a uniform ice density of $917 \mathrm{~kg} / \mathrm{m}^{3}$ to convert SEC observed volume to mass may overestimate the actual GrIS, especially in areas with high altitudes. Different densities for volume converted into mass were tested and the corresponding scale factors and its scaled GRACE-based results were estimated (see Figure S6). The gridded scaling factors did not significantly change due to the mass change derived by various densities. The final restored GRACE results varied within $\pm 10 \mathrm{Gt}$, which indicates that the spatial distribution and magnitude of SEC is the dominant factor in determining the scaling factors for ice mass. Moreover, SMB and SEC here were mainly used to identify the attenuation or leakage caused by truncation and filtering of ice mass changes and its loading crustal response. Based on the weighted average of scaling factors estimated from SMB and SEC, the simulation errors of the respective models themselves in different regions will be minimized.

The gridded scaling factors for GrIS mass change on a $0.5^{\circ} \times 0.5^{\circ}$ grid were estimated from the SMB and SEC model (shown in Figure S7) by applying the restoring signal attenuation method of Landerer and Swenson (2012). Three sets of gridded scale factors from SMB, SEC and their weighted average were applied (Figure 3a) to the corresponding filtered GRACE-derived mass variations, and then the re-scaled results for all grid points (Figure 3b) were spatially averaged to obtain the final time series of GrIS changes (Figure 3c). The scaled linear trend rate $(-272 \pm 6 \mathrm{Gt} / \mathrm{yr})$, estimated with the weighted averaged (SMB and SEC) scaling factors, were restored, and nearly double the original non-scaled signal $(-139 \pm 2$ Gt/yr) from 2003 to 2015 for the entire GrIS region. This included a total of 2133 grids with $0.5^{\circ}$ spatial resolution, except all exposed rock or floating ice. Figure $3 \mathrm{c}$ shows that the rescaled GRACE results from a single model over- or underestimated ice mass changes. Thus, the median scaling factors estimated from the ensemble of two model (SMB and SEC) simulations do make the re-scaling more robust.

We also compared the weighted scaled GRACE of this study with those obtained in previous studies with same fitting time spans (Table S1). The result indicates that our 
estimates were more or less in agreement with the reported GRACE-derived mass loss rate from previously published results, but those published studies used different processing methods and different GIA models. Therefore, it is difficult to effectively compare the results. With the rise of alternative methods in recent years, using regional mass concentration functions (mascons) to parameterize Earth's gravity field (ex. JPL mascon solutions from Watkins et al., 2015 and CSR mascon solutions from Save et al., 2016) is considered a fundamentally different approach to applying constraints. Thus, we also derived the estimate of ice mass loss from the CSR mascon solutions (CSR-M) and JPL mascon solutions (JPL-M) for the same time spans and included them in the comparison of various mass loss estimates (see Figure S8 and Table S1). The CSR-M and JPL-M solutions were both represented on $0.5^{\circ}$ grids and the same processing with this study, including: the $C_{20}$ coefficients replaced by Cheng et al. (2013); the degree-1 coefficients corrections applied from Swenson et al. (2008); the atmospheric and non-tidal oceanic effects removed using the GRACE AOD1B RL05 products; and the contributions from Glacial Isostatic Adjustment (GIA) removed by A et al. (2013). Our scaled GRACE-based GrIS mass loss ( $-272 \pm 6$ Gt/yr) was lower than the estimates $(-289 \pm 29 \mathrm{Gt} / \mathrm{yr})$ from JPL-M solutions but higher than the results from CSR-M solutions $(-263 \pm 30 \mathrm{Gt} / \mathrm{yr})$. The underestimation of our results likely comes from the effects of spatial constraints; for instance, we only restored the GrIS area (a total of 2133 grids with $0.5^{\circ}$ spatial resolution) instead of the entire Greenland continent (a total of 2679 grids with $0.5^{\circ}$ spatial resolution), and CSR-M (Save et al., 2016) did not apply the land/ocean leakage correction like JPL-M from Watkins et al. (2015). Therefore, using CSR-M to estimate the mass loss in the ice regions requires an extended regional kernel at least $120 \mathrm{~km}$ into the ocean. Although JPL-M applied a Coastline Resolution Improvement (CRI) filter to separate land and ocean portions of mass (Watkins et al., 2015), it still reflects the mass change of all of Greenland rather than the contribution of pure GrIS. The impact of this may cause a difference between mass loss rates from this study and most previous studies.

3.2 Comparison between GPS-observed and scaled GRACE-derived vertical displacement variations

The scaling factors derived from the model-predicted vertical displacements (Section 2.4) showed remarkable spatial heterogeneity that reflects the characteristics of melting GrIS ice (Figure 4a). These results are the weighted average of the scaling factors basing on a synthetic model from SMB and SEC data (Figure S9). The scaling factors over the GrIS boundary regions had values $>1$, evidence for greater ice loss at lower elevations compared to high altitude areas $(>2000 \mathrm{~m})$. This is especially the case along the western, southeastern, and northeastern margins, where the highest values across the boundary of the glacier systems occurred. Here, the mass loss of the dynamically thinning glaciers was not able to be resolved due to the low-pass filtering. In this case, a higher factor $(>3)$ was required to restore the signal.

The unscaled vertical displacement uplift derived from GRACE (Figure 4b) multiplied by the scaling factors (Figure 4a) was used to obtain the downscaled GRACE prediction of the uplift in Greenland (Figure 4c). The scaled results show the rates of GRACE-derived vertical displacements ranging from -2 to $14 \mathrm{~mm} / \mathrm{yr}$ during 2003 to 2015 . At the basin scale, the scaled uplifts predicted from GRACE effectively identified the spatial differences of the uplift due to regional variability in ice loss. Figure $4 \mathrm{c}$ shows a significant uplift caused by apparent dynamic processes in the southeast, northeast, central west, and northwest of GrIS. 
GPS-observed vertical displacements (after correction for atmospheric pressure, nontidal ocean and GIA) were used to evaluate GRACE predictions for the crustal uplift at GNET sites (Figure S10). The entire network is uplifting due to the Earth's elastic response to present-day GrIS changes, assuming that GIA has been completely removed, and the GRACE estimates were less than the GPS estimates at almost all GPS stations due to different sensitivities to the concentrated mass loss along the ice sheet margin. Three GPS sites (KELY, QAQ1 and WTHG) were used as examples to evaluate the consistency between the scaled GRACE-predicted and GPS-observed uplift in the three basins of Greenland (Figure 4d). Note that these three stations with different uplift amplitudes are located in areas with different levels of ice mass loss. More importantly, the locations selected were less affected according to the GIA model. Thus, errors in the GIA correction had less influence on the scaling factors at these stations. Also, an uplift anomaly at many of the GNET stations (including KELY and QAQ1) occurred from 2010 to 2012 (blue background area in Figure 4e). These anomalous uplifts spatially correlated with the 2010 melting day anomaly also found by Bevis et al. (2012). Both GRACE and GPS observations indicated an acceleration of ice mass loss in the southern of GrIS drainage basins (SE, SW and CW basins in Figure S10). This anomalous oscillation of ice loss that agrees with previous results is very likely because Greenland temperatures increased in 2010 due to the north Atlantic oscillation contributing to a warm summer and reducing surface albedo (Bevis et al., 2012; Forsberg et al., 2017). The extreme melt event across almost the entire surface of the GrIS in July 2012 was because of an unusually strong warm air in the region (Box et al., 2012; Nghiem et al., 2012).

To focus on the time-variable feature, the short-term and long-term monthly time series of GPS-observed and scaled GRACE-derived vertical displacements were quantitatively analyzed. The selected sites shown in Figure 4e indicates highly consistent seasonal (annual and semi-annual) and long-term vertical displacements between scaled GRACE and GPS, as indicated by the very similar amplitude and phase of seasonal characteristics and consistent uplift patterns due to the load change. Table S3 provides the detailed quantitative evaluation results for seasonal amplitudes, correlation, and WRMS (Weighted Root-Mean-Squares) reduction between GPS and scaled GRACE vertical displacements. The reductions of WRMS obtained by GPS-observed, subtracting the scaled GRACE-derived results, were computed by following the equation described by previous works (e.g., van Dam et al., 2007; Fu et al., 2012). Figure 5 shows the percentage of WRMS reductions for each GNET station is very significant, especially in SE, SW and CW basins WRMS reduction is more than $60 \%$, but WRMS reduction is relatively small (less than $50 \%$ ) in the NO and NE regions.

\subsection{GPS-to-GRACE ratio}

We estimated GPS-to-GRACE ratios from the model predictions and compared them with observed ratios at each GPS site. Table S2 lists the results in terms of least square fit linear trends between observations and predictions. The correlation between predicted and observed ratios, as shown in Figure 6, shows that sites with large observed ratios tend to have large predicted ratios. However, the correlation is weak in north Greenland (left of Figure $6 a)$, and the lesser observed GPS-to-GRACE ratios (0.3 0.8) contradict corresponding predicted ratios, which were relatively large ranging from 0.9 to 2 . These differences are evidence that the GPS-to-GRACE ratios are influenced by other factors beyond just the true model signals. For instance, these factors may include the sensitivity kernel and inconsistencies of the reference frame between GPS and GRACE, the uncertain GIA correction, and/or Green's functions or loading Love numbers not reflecting realistic earth 
models. In this study, the GPS data was corrected by the 'GNET-GIA' model inferred from Khan et al. (2016). The GRACE data was corrected using the GIA model from A et al. (2016) based on ICE-5G. Thus, some differences in the GIA model are very likely to appear when computing GPS-to-GRACE ratios.

Here, we tested three other GIA correction strategies including 1) not considering the effects of GIA, 2) GPS and GRACE both using 'GNET-GIA' for correction and 3) both using A et al.'s (2013) model for correction. Comparison results indicate the observed GPS-toGRACE ratios after processing by the above three strategies were generally poorly correlated with the predicted GPS-to-GRACE ratios (right of Figure 6a). The observed GPS-to-GRACE ratio obtained by using our initial processing (slope is 0.8 shown in left of Figure 6a) was significantly closer to the predicted ratio than the other three options (slope is $0.3,-0.08$ and 0.39 shown in right of Figure 6a respectively for no GIA corrected, 'GNET-GIA' and A et al.'s model corrected). This result confirms that different GIA correction models need to be considered for in-situ and satellite observations due to differences in observation resolution.

Figure $6 \mathrm{~b}$ shows observed and predicted GPS-to-GRACE ratios as a function of a distance from GPS sites to the margins of the GrIS. The ratios decreased with distance, which is a consequence of the fact that GPS measurements are more sensitive to mass loss at smaller scales, but GRACE-derived uplifts are proportionally smoothed so that mass loss within 50 kilometers from site to load has an effect. When the distance to the glacier edge increased, the ratio decreased to about $0.6 \sim 0.8$ when at a distance of $150 \mathrm{~km}$. At this distance, the displacement amplitudes due to the ice loss were difficult detected in the GPS records. In contrast, the GRACE monitoring signals decreased due to the impact of load sources within a few hundred kilometers or the effects of the reference frame and GIA corrections between GPS and GRACE (see the detailed discussion in Section 4.2 below).

Figure $6 \mathrm{~b}$ also shows the global Green's functions for vertical displacement for the PREM model. The Green's functions mimic the negative trend of the GPS-to-GRACE ratios for distant zones located less than $\sim 200 \mathrm{~km}$ from the loading point. Thus, GPS-to-GRACE ratios are mostly sensitive to the local crustal elastic properties (Bevis et al., 2015; Durkin et al., 2019) and to the structure of nearby mass loss. Also, the observed GPS-to-GRACE ratios based on 'GNET-GIA' to correct the GPS values and A et al.'s (2103) model to correct GRACE (left in Figure 4b) were much closer to the Green's functions than results corrected by the other three methods (right in Figure 4b). This indicates that the GPS-to-GRACE ratios after removing GIA effects reflect the sensitivity of GPS and GRACE observations with loads at various distances.

Farrell (1972) computed the loading Green's functions for the Gutenberg-Bullen standard Earth model; the loading Green's functions for PREM are given for different Moho depths in the ocean and continents by Jentzsch (1997). A comparison of these Green's functions reveals only slight differences. However, for distances $<3^{\circ}(\sim 300 \mathrm{~km})$, the local crustal structure becomes important for the Green's functions amplitude (Dill et al., 2015). For example, lateral deviations in surface deformation due to the local elastic properties of the lithosphere (maximum changes $51 \%$ in the vertical and $146 \%$ in the horizontal displacements as found by Dill et al., 2015) are found to be much greater than differences between various commonly used one-dimensional Earth models (e.g., larger differences of Green's functions are found with magnitudes larger than $26 \%$ in the vertical and $72 \%$ in the horizontal displacements, as described by Wang et al., 2012). In fact, the solid-earth elastic response to the loading mass itself should be taken into account for realistic load perturbations, and most of the GNET sites are located in areas with sharp loading changes 
where the largest mass loading signals are likely associated with dynamic changes in ice loss in neighboring glaciers.

It is worth noting that the downscaled GRACE results depend on the resolution of the synthetic model (e.g., spatial resolution of $\sim 5 \mathrm{~km} \times 5 \mathrm{~km}$ for SEC and $\sim 11 \mathrm{~km} \times 11 \mathrm{~km}$ for SMB). Therefore, the scaled GRACE-derived vertical displacements make it difficult to estimate a correct elastic response to the ice loss when any GPS station is near the edge of the GrIS, typically within $\sim 5 \mathrm{~km}$ of a margin with major ice loss. In this case, the ice loss often increases towards the edge of the ice, which is especially true when the ice front is retreating. Typically, ice loss per unit area within $1 \mathrm{~km}$ of the station is considerably greater than ice loss between 1 and $2 \mathrm{~km}$, which is in turn greater than ice loss per unit area between 2 and $3 \mathrm{~km}$ from the station. The GRACE derived mass changes were smoothed with a Gaussian filter, which reduced their spatial resolution to $\sim 330 \mathrm{~km}$. Consequently, highly concentrated mass changes with smaller sizes are 'spread out' or blurred. Such smoothing inevitably reduces peak amplitudes of the mass loss per unit area. As a result, GRACE derived mass changes near the edge of the ice margins tend to under-predict the elastic response at any GPS station located near any intense but localized mass loss anomaly. This might cause significant underestimation of the elastic signal at GPS stations located $2-5 \mathrm{~km}$ from the ice front. In Figure $6 c$, the colored dots for observed GPS-to-GRACE ratios show this effect in the range 0-15 km. Cyan dots represent virtually no ice loss (such as large parts of the north and northeast GrIS), green dots show margins with significant but smoothly distributed ice loss and red dots, indicating margins that are retreating and therefore losing large amounts of ice mass very close to the edge. Locations with the majority of the red dots are very consistent with the glacier front position at the twenty major outlet glaciers.

\section{Discussions}

\subsection{Mass-loading sensitivity scales}

The above analysis demonstrates that GPS measurements and the GRACE predictions of crustal motion are sensitive to the present-day mass imbalance of the GrIS at different scales. Here, we mapped the difference upper degree limit (i.e., $l_{\max }=\infty$ vs $l_{\max }=60$ ) of the loading Green's function for the GPS stations at each GrIS mask grid point $\left(0.5^{\circ}\right)$, which illustrates how sensitive GNET is to mass loading of different spatial resolutions with which a loading field is represented. First, the distribution of the loading Green's function was calculated corresponding to each GNET site, the vertical displacements caused by the signal corresponding to a 1-meter water thickness spread over $1000 \mathrm{~km}^{2}$ were obtained. These results are shown for all GrIS points in Figure 7. The vertical displacement Green's function at GPS scales (upper limit $l_{\max }=\infty$ ) and at GRACE scales (upper limit $l_{\max }=60$ ) indicate that GPS and GRACE estimates provide a weighted average of the mass loss across a load area for different sensitivity ranges, where the weighting is determined by the load Green's function and is not uniform across the drainage basin (Wahr et al., 2013).

Also, the GRACE sensitivity kernel (upper limit $l_{\max }=60$ ) is wider than the GPS kernel (upper limit $l_{\max }=\infty$ ), and the black solid curve in Figure 7 represents the mean value of the loading Green's functions for all stations. Our results also confirmed that the resolution of the GRACE data is not sufficient to separate the source of the mass loss in GrIS (Khan et al., 2010) because the vertical displacement Green's function for the upper limit is $l_{\max }=60$. Basically, the difference between the GRACE-predicted and GPS-observed uplift rates depend on the location of the GPS stations, because the GPS uplift rates are primarily related to the mass loss in the vicinity of station, which is also most significant along the ice sheet margin (Khan et al., 2010). Conversely, when there is no obvious mass loss near a station, or 
when it is far away from the ice sheet, mass loss causing uplift is exposed much more clearly in GRACE than in GPS. This is mainly caused by the wide sensitivity kernels of GRACE a larger range of sources allowing to be captured. Consequently, the observed GPS-GRACE ratio was less than 1 at most GNET stations in north and northeast Greenland (Figure 6). Obviously, the accelerated mass loss in the north and northeast was much less than that in the south for this time period (Figure 1b), primarily affected by dynamic contributions from the ice sheet interior rather than by changes in the marine-terminating outlet glaciers located along the coast.

\subsection{The effects of Reference Frame and GIA Corrections between GPS and GRACE}

Different reference frames exist for both GPS (CF reference frame) and GRACE (the

CM frame) data. To keep the reference frame consistent between GPS and GRACE, previous studies have essentially used two methods to solve this issue. One is the method described above in Section 2.2 of this study, which is to insert degree- 1 terms into the GRACE spherical harmonic fields to make GRACE compatible with the GPS reference frame (e.g., Davis et al., 2004; Tregoning et al., 2009; Fu et al., 2012, etc.). The second method is removing the geocentric motion time series from the GPS data, which will transform to the results in the CM frame (e.g., van Dam et al., 2007; Tesmer et al., 2011). In theory, both of these methods should be able to maintain consistency in the reference frame between GPS and GRACE, but we should clarify that different methods using different data sets will definitely make a difference in the results. Thus, the error of Degree-1 terms derived by Swenson et al. (2008) used in this paper might be reflected in the uncertainty of the GPS-toGRACE ratios.

Additionally, the predicted GPS-to-GRACE ratio exceeds the observed ratios in north and northeast Greenland (Figure 6a), as these are caused by the larger uplift rate of the GRACE predictions than those recorded by the GPS measurements (Figure 3). Khan et al. (2010) found that the uplift rate differences between GRACE and GPS might be caused, for instance, by a reference frame drift in the GPS results, secular fitting errors in either GRACE or GPS results, or errors in the GIA estimates. Previous studies showed that the GPS terrestrial reference frame center is consistent with satellite laser ranging at a centimeter level with a drift less than $1 \mathrm{~mm} /$ year (Collilieux et al., 2011). Khan et al. (2010) used the difference in the z-component $1.8 \mathrm{~mm} / \mathrm{yr}$ as a proxy for the uncertainty due to reference frame drifts. Even though significant improvements for the reference frame have been made in the GPS analysis over the past decade, some of these errors are not well understood or corrected for, and thus may still remain in our results. This study only considers near-field deformation rates, which are dominated by the direct effect of the individual GrIS melt sources. In the far field, i.e., several hundred kilometers away from region of ice mass loss, several interannual and secular processes can lead to long-term vertical deformation rates at the $\mathrm{mm} / \mathrm{yr}$ level (Riva et al., 2017).

More importantly, the uncertainties of GIA vertical displacement rates require more consideration in both GPS and GRACE estimates. Secular errors between the GPS correction using observed GIA rates from 'GNET-GIA' (Khan et al., 2016) and the GRACE correction using the GIA model from A et al. (2013) most likely affect uplift rates caused by presentday mass loss. Therefore, the GIA vertical displacements of "GNET-GIA" was compared to the model from A et al. (2013). Figure 8 shows the GIA uplift rates for Greenland computed with the Stokes coefficients of A et al. (2013), which are based on the ICE-5G ice history and the VM2 viscosity profile (Peltier, 2004) and most frequently applied in Greenland from previous studies (see Table S1) and mascon products (Watkins et al., 2015; Save et al., 2016), and the 'GNET-GIA' inferred GIA uplift rates for GNET. Similar patterns are visible in 
north, central east and south Greenland, but the 'GNET-GIA' observed rates in the southeast and northwest are significantly greater and more localized compared to model predictions of A et al. (2013). Fleming and Lambeck (2004) showed that the regional adjustment of the initial load history is poorly constrained in southeast and northwest Greenland because of a lack of relative sea-level evidence. Khan et al. (2016) explain those large observed uplift rates in the southeast as being caused by ice loss during the past century, assuming a relatively weak Earth structure with a thin lithosphere and low-viscous asthenosphere.

We also found that several GNET sites with large differences between the 'GNETGIA' and A et al. (2013) models do not show distinct differences in the GPS-to-GRACE ratio. For example, the GIA uplift rates from 'GNET-GIA' were $12.0 \mathrm{~mm} / \mathrm{yr}, 10.3 \mathrm{~mm} / \mathrm{yr}$ and $6.2 \mathrm{~mm} / \mathrm{yr}$ at KUAQ, MIK2 and PLPK located in southeast Greenland, respectively, but the observed GPS-to-GRACE ratios are in a good agreement with the prediction from the SMB and SEC models (Table S2). Our results indicate that the localized pattern of the largest uplift is associated with the low-viscosity region in southeast Greenland, and this required us to consider different upper limits of the GIA model's degree and order (e.g., $l_{\max }=\infty$ vs $l_{\max }=60$ ) when we corrected the GIA for GPS or GRACE. Consequently, we chose different processing strategies in GPS and GRACE corrections using the high resolution 'GNET-GIA' and lower resolution model predictions from A et al. (2013). However, the 'GNET-GIA' observed rates in northeast Greenland were slightly smaller than the model predictions, because this region is most sensitive to errors in deglaciation models. GIA effects in the northeast computed by A et al. (2013) are in good agreement with the results of Sutterley et al. (2014) based on the SM09-GIA model, and slightly larger than the GREEN1 model (Fleming and Lambeck, 2004) presented by Khan et al. (2016). The different uplift rates in the northeast specifically between the models mentioned above suggest that different deglaciation histories or Earth's viscosity profiles represent a source of uncertainty for crustal displacement estimates from GRACE and GPS. For example, overcorrection of GIA leads to a small GPS-observed uplift rate and, consequently, to a small ratio.

\section{Conclusions}

In this paper, we presented a downscaling method of GRACE-predicted uplift response to present-day mass loss in Greenland. The relationship between uplift and surface masses at different spatial scales indicates that GPS measurements and GRACE predictions of crustal motion are close to the maximum degree of the loading Green's function. We demonstrated how SMB and SEC gridded data, which represent the spatial distribution of the surface mass balance and the dynamic glacier contributions, can be used to generate scaling factors to downscale GRACE signals. The forward modeling results show that the gridded scaling factors at the $0.5^{\circ} \times 0.5^{\circ}$ scale from SMB and SEC models show obvious spatial heterogeneity due to significant mass losses concentrated along the GrIS margin, and relatively small changes in the elevated GrIS interior. The GRACE-derived mass trend for the entire GrIS region is $-272 \pm 6 \mathrm{Gt} / \mathrm{yr}$ when using scaling factors from the weighted average of SMB and SEC from 2003 to 2015. Our scaled GRACE-based GrIS mass loss was slightly different with previously published results, e.g., our scaled results lower than estimates from JPL-M solutions but higher than CSR-M solutions (Table S1 and Figure S8). Those underestimated or overestimated GRACE-based GrIS mass loss are likely due to the different spatial constraints between this study and others, particularly because we only restored the GrIS area versus the entire Greenland as most previous research has conducted. The scaling factors of the vertical displacements reached values $>1$ within the GrIS boundary regions, and even exceed values of 3 at dynamically thinning glaciation points. The scaled GRACEderived uplift trends are in the $-2-14 \mathrm{~mm} / \mathrm{yr}$ range for the entire region from 2003 to 2015. 
Our scaled GRACE predictions also provide evidence for a significant uplift caused by dynamic processes in the southeast, central west, northwest and northeast.

Three sample GNET sites (KELY, QAQ1 and WTHG) are consistent between the GPS-observed and scaled GRACE-derived seasonal (annual and semi-annual) and long-term vertical displacements in the three different regions of Greenland. We also quantitatively evaluated the time-variable feature of GPS and scaled GRACE at GNET sites. There is a high correlation and significant percentage of WRMS reductions (Table S3), especially in the southeast, southwest, and central west basins where there are obvious GrIS mass losses. We also compared GPS-to-GRACE ratios, which reflect the accuracy of the GRACE uplift predictions, at 53 GNET sites. This comparison showed many sites where large observed ratios corresponded to large predicted ratios. The latter suggests that GRACE-based predictions perform well overall except for sites close to regions of concentrated loads, in which they underestimate the vertical displacements. However, the correlation between predicted and observed GPS-to-GRACE ratios is weak in north Greenland, with smaller observed ratios varying between $0.3 \sim 0.8$ while the predicted ratios ranging 0.9 to 2 are relatively large.

Furthermore, we evaluated the effect of the sensitivity kernels and the uncertainties of the GIA correction on differences between predictions and observations. GPS and GRACE estimates are based on weighted averages of mass loss in different sensitivity ranges. Large GPS-to-GRACE ratio errors likely correspond to areas with large GIA uncertainties. Thus, combining GRACE and GPS to estimate long-term load deformations requires an absence of concentrated load signals near the site, or the estimates of the scaling factor should be based on a reliable mass change model around the site. This study is valuable for assessing the GRACE-based crustal response to TWS anomalies at regional or global scales and help to determine the appropriate use of downscaling approaches to correct GRACE signals for studying other processes, e.g., crustal motions caused by tectonic movements and TWS loss (e.g., lakes and groundwater) induced by human activities.

\section{Acknowledgments}

We thank the Editor, P. Tregoning, M. King and one anonymous reviewer for their insightful comments, which helped to improve this manuscript. The GNET data in this study was provided by Dr. S. A. Khan. We thank all the researchers for their valuable contributions to the GNET fieldwork. The Release-05 GRACE Level-2 spherical harmonics solutions provided by CSR are available from NASA

(ftp://podaac.jpl.nasa.gov/allData/grace/L2/CSR/RL05/). The CSR GRACE RL05 mascons solutions can be downloaded from CSR (http://www.csr.utexas.edu/grace/). The JPL GRACE RL05 mascons solutions can be found from NASA (ftp://podaac.jpl.nasa.gov/allData/tellus/L3/mascon/RL05/JPL/). The RACMO SMB fields were produced in the Institute for Marine and Atmospheric Research of Utrecht University (https://www.projects.science.uu.nl/iceclimate/models/). The ICESat data can be downloaded from the NASA National Snow and Ice Data Center (http://nsidc.org/data/glah12) and the CryoSat-2 satellite altimetry data are available from the European Space Agency (https://earth.esa.int/web/guest/data-access). A more detailed discussion of GRACE derived mass change trends in Greenland can be found in the supporting information (Velicogna and Wahr, 2006; Schrama and Wouters, 2011; Schrama et al., 2014; Jin and Zou, 2015; Paulson et al., 2007). We also thank the National Natural Science Foundation of China (41504065, 41874090, 41574070 and 41774091) for supporting this work. Additional data used in this paper are available upon request to the authors. 


\section{References}

A, G. R., Wahr, J. \& Zhong, S. (2013), Computations of the viscoelastic response of a 3-D compressible Earth to surface loading: An application to Glacial Isostatic Adjustment in Antarctica and Canada. Geophysical Journal International, 192, 557-572. doi:10.1093/gji/ggs030

Bevis, M., Alsdorf, D., Kendrick, E., Fortes, L. P., Forsberg, B., Smalley Jr. R., \& Becker, J. (2005). Seasonal fluctuations in the mass of the Amazon River system and Earth's elastic response. Geophysical Research Letters, 32, L16308. doi:10.1029/2005GL023491

Bevis, M., Wahr, J., Khan, K. A., et al. (2012). Bedrock displacements in Greenland manifest ice mass variations, climate cycles and climate change. Proceedings of the National Academy of Sciences, 109(30), 11944-11948. doi:10.1073/pnas.1204664109

Bevis, M., E. Pan, H. Zhou, F. Han \& R. Zhu (2015). Surface deformation due to loading of a layered elastic half-space: Constructing the solution for a general polygonal load, Acta Geophysica, 63 (4), 957-977. doi:10.1515/acgeo-2015-0034

Bevis, M. et al. (2019). Accelerating changes in ice mass within Greenland, and the ice sheet's sensitivity to atmospheric forcing. Proceedings of the National Academy of Sciences, 116. doi:10.1073/pnas.1806562116

Box, J. E., Fettweis, X., Stroeve, J. C., Tedesco, M., Hall, D. K., \& Steffen, K. (2012). Greenland ice sheet albedo feedback: Thermodynamics and atmospheric drivers. The Cryosphere, 6, 821-839. doi:10.5194/tc-6-821-2012

Cheng, M., Tapley, B. D., \& Ries, J. C. (2013). Deceleration in the Earth's oblateness. Journal of Geophysical Research: Solid Earth, 118, 740-747. doi:10.1002/jgrb.50058 Chen, X., Zhang, X., Church, J. A., Watson, C., King, M., Monselesan, D., Legresy, B., \& Harig, C. (2017). The increasing rate of global mean sea-level rise during 1993-2014. Nature Climate Change, 7, 492-495. http://doi.org/10.1038/nclimate3325

Collilieux, X., Métivier, L., Altamimi, Z., van Dam, T., \& Ray, J. (2011). Quality assessment of GPS reprocessed terrestrial reference frame. GPS Solutions, 15, 219-231.

doi:10.1007/s10291-010-0184-6

Davis, J. L., Elósegui, P., Mitrovica, J. X., \& Tamisiea, M. E. (2004). Climate-driven deformation of the solid earth from GRACE and GPS. Geophysical Research Letters, 31, L24605. doi:10.1029/2004GL021435

Dill, R., Klemann, V., Martinec, Z., \& Tesauro, M. (2015). Applying local Green's functions to study the influence of the crustal structure on hydrological loading displacements. Journal of Geodynamics, 88, 14-22. doi:10.1016/j.jog.2015.04.005

Durkin, W., S. Kachuk \& M. Pritchard (2019). The importance of the inelastic and elastic structure of the crust in constraining glacial density, mass change, and isostatic adjustment from geodetic observations in Southeast Alaska, Journal of Geophysical Research: Solid Earth, 124. doi:10.1029/2018JB016399

Dziewonski, A. M., \& Anderson, D. L. (1981). Preliminary reference Earth model. Physics of the Earth and Planetary Interiors, 25, 297-356. doi:10.1016/0031-9201(81)90046-7

Farrell, W. E. (1972). Deformation of the Earth by surface loads. Reviews of Geophysics, 10, 761-797. doi:10.1029/RG010i003p00761

Fleming, K., \& Lambeck, K. (2004). Constraints on the Greenland ice sheet since the Last Glacial Maximum from sea-level observations and glacial-rebound models. Quaternary Science Reviews, 23, 1053-1077. doi:10.1016/j.quascirev.2003.11.001

Forsberg, R., Sørensen, L., \& Simonsen, S. (2017). Greenland and Antarctica ice sheet mass changes and effects on global sea level. Surveys of Geophysics, 38, 89-104.

doi:10.1007/s10712-016-9398-7 
Fu, Y., Freymueller, J. T., \& van Dam, T. (2012). The effect of using inconsistent ocean tidal loading models on GPS coordinate solutions. Journal of Geodesy. 86, 409-421, doi:10.1007/s00190-011-0528-1

Gardner, A. S., Moholdt, G., Cogley, J. G., et al. (2013). A reconciled estimate of glacier contributions to sea level rise: 2003 to 2009. Science, 340, 852-857.

doi:10.1126/science.1234532

Han, D., \& Wahr, J. (1995). The viscoelastic relaxation of a realistically stratified Earth, and a further analysis of post-glacial rebound. Geophysical Journal International, 120, 287-311. doi:10.1111/j.1365-246X.1995.tb01819.x

Hao, M., Freymueller, J. T., Wang, Q., Cui, D. \& Qin, S. (2016). Vertical crustal movement around the southeastern Tibetan Plateau constrained by GPS and GRACE data. Earth and Planetary Science Letters. 437, 1-8. doi:10.1016/j.epsl.2015.12.038

Jacob, T., Wahr, J., Pfeffer, W. T., \& Swenson, S. (2012). Recent contributions of glaciers and ice caps to sea level rise. Nature, 482, 514-518. doi:10.1038/nature10847

Jentzsch, G. (1997). Earth Tides and Ocean Tidal Loading. Tidal Phenomena, Berlin, Heidelberg: Springer. 66, 145-171. doi:10.1007/BFB0011461

Jin, S. G., \& Zou, F. (2015). Re-estimation of glacier mass loss in Greenland from GRACE with correction of land-ocean leakage effects. Global and Planetary Change, 135, 170-178. doi:10.1016/j.gloplacha.2015.11.002

Khan, S. A., Sasgen, I., Bevis, M., et al., (2016). Geodetic measurements reveal similarities between post-Last Glacial Maximum and present-day mass loss from the Greenland Ice Sheet. Science Advances, 2, e1600931. doi:10.1126/sciadv.1600931

Khan, S. A., Wahr, J., Leuliette, E., van Dam, T., Larson, K. M., \& Francis, O. (2008). Geodetic measurements of postglacial adjustments in Greenland. Journal of Geophysical Research: Solid Earth. 113, B02402. doi:10.1029/2007JB004956

Khan, S. A., Wahr, J., Bevis, M., Velicogna, I., \& Kendrick, E. (2010). Spread of ice mass loss into northwest Greenland observed by GRACE and GPS. Geophysical Research Letters, 37, L06051. doi:10.1029/2010GL042460

Kusche, J., \& Schrama, E. J. O. (2005). Surface mass redistribution in- version from global GPS deformation and Gravity Recovery and Climate Experiment (GRACE) gravity data.

Journal of Geophysical Research: Solid Earth, 110, B09409. doi:10.1029/2004JB003556 Landerer, F. W., \& Swenson, S. C. (2012). Accuracy of scaled GRACE terrestrial water storage estimates. Water Resources Research, 48, W04531. doi:10.1029/2011WR011453 Li, J., \& Zwally, H. J. (2011). Modeling of firn compaction for estimating ice-sheet mass change from observed ice-sheet elevation change. Annals of Glaciology, 52(59), 1-7. doi:10.3189/172756411799096321

Liu, L., Khan, S. A., van Dam, T., Ma, J. H. Y., \& Bevis, M. (2017). Annual variations in GPS-measured vertical displacements near Upernavik Isstrøm (Greenland) and contributions from surface mass loading. Journal of Geophysical Research: Solid Earth, 122, 677-691. doi:10.1002/2016JB013494

Long, D., Longuevergne, L., \& Scanlon, B. R. (2015). Global analysis of approaches for deriving total water storage changes from GRACE satellites. Water Resources Research, 51, 2574-2594. doi:10.1002/2014WR016853

Lyard, F., Lefevre, F., Letellier, T., \& Francis, O. (2006). Modelling the global ocean tides: modern insights from FES2004. Ocean dynamics, 56, 394-415. doi:10.1007/s10236-0060086-X

McMillan, M., et al. (2016). A high-resolution record of Greenland mass balance. Geophysical Research Letters, 43, 7002-7010. doi:10.1002/2016GL069666 
Nghiem, S. V., Hall, D. K., Mote, T. L., Tedesco, M., Albert, M. R., Keegan, K., Shuman, C. A., DiGirolamo, N. E., \& Neumann, G. (2012). The extreme melt across the Greenland ice sheet in 2012. Geophysical Research Letters, 39, L20502. doi:10.1029/2012GL053611 Noël, B., van de Berg, W. J., van Wessem J. M., et al. (2018). Modelling the climate and surface mass balance of polar ice sheets using RACMO2-Part 1: Greenland (1958-2016). The Cryosphere, 12, 811-831. doi:10.5194/tc-12-811-2018

Noël, B., van de Berg, W. J., Machguth, H., Lhermitte, S., Howat, I., Fettweis, X., \& van den Broeke, M. R. (2016). A daily, $1 \mathrm{~km}$ resolution data set of downscaled Greenland ice sheet surface mass balance (1958-2015). The Cryosphere, 10, 2361-2377. doi:10.5194/tc-10-23612016

Paulson A., Zhong, S. \& Wahr, J. (2007). Inference of mantle viscosity from GRACE and relative sea level data. Geophysical Journal International, 171, 497-508. doi:10.1111/j.1365246X.2007.03556.x

Peltier, W. R. (2004). Global glacial isostasy and the surface of the Ice-Age Earth: The ICE5G (VM2) model and GRACE. Annual Review of Earth and Planetary Sciences, 32, 111149. doi:10.1146/annurev.earth.32.082503.144359

Rignot, E., Velicogna, I., van den Broeke, M. R., Monaghan, A., \& Lenaerts, J. (2011). Acceleration of the contribution of the Greenland and Antarctic ice sheets to sea level rise. Geophysical Research Letters, 38, L05503. doi:10.1029/2011GL046583

Riva, R. E. M., Frederikse, T., King, M. A., Marzeion, B., \& van den Broeke, M. R. (2017). Brief communication: The global signature of post-1900 land ice wastage on vertical land motion. The Cryosphere, 11, 1327-1332. doi:10.5194/tc-11-1327-2017

Sasgen, I., van den Broeke, M. R., Bamber, J. L., et al. (2012). Timing and origin of recent regional ice-mass loss in Greenland. Earth and Planetary Science Letters, 333-334: 293-303. doi:10.1016/j.epsl.2012.03.033

Save, H., Bettadpur, S., \& Tapley, B. D. (2016). High resolution CSR GRACE RL05 mascons. Journal of Geophysical Research: Solid Earth, 121, 7547-7569. doi:10.1002/2016JB013007

Schrama, E. J. O., \& Wouters, B. (2011). Revisiting Greenland ice sheet mass loss observed by GRACE. Journal of Geophysical Research: Solid Earth, 116, B02407.

doi:10.1029/2009JB006847

Schrama, E. J. O., Wouters, B., \& Rietbroek, R. (2014). A mascon approach to assess ice sheet and glacier mass balances and their uncertainties from GRACE data. Journal of Geophysical Research: Solid Earth, 119, 6048-6066. doi:10.1002/2013JB010923

Shepherd, A., Ivins E. R., A, G., et al. (2012). A reconciled estimate of ice-sheet mass balance. Science, 338, 1183-1189. doi:10.1126/science.1228102

Simonsen, S. B., \& Sørensen, L. S. (2017). Implications of changing scattering properties on Greenland ice sheet volume change from Cryosat-2 altimetry. Remote Sensing of

Environment, 190, 207-216. doi:10.1016/j.rse.2016.12.012

Simpson, M. J. R., Milne, G. A., Huybrechts, P., \& Long, A. J. (2009). Calibrating a glaciological model of the Greenland ice sheet from the Last Glacial Maximum to presentday using field observations of relative sea level and ice extent. Quaternary Science Reviews, 28, 1631-1657. doi:10.1016/j.quascirev.2009.03.004

Sun, A. Y. (2013). Predicting groundwater level changes using GRACE data. Water Resources Research, 49, 5900-5912. doi:10.1002/wrcr.20421

Sutterley, T. C., Velicogna, I., Csatho, B., van den Broeke, M. R., Rezvan-Behbahani, S., \& Babonis, G. (2014). Evaluating Greenland glacial isostatic adjustment corrections using GRACE, altimetry and surface mass balance data. Environmental Research Letters, 9, 014004. doi:10.1088/1748-9326/9/1/014004 
Swenson, S., Chambers, D., \& Wahr, J. (2008). Estimating geocenter variations from a combination of GRACE and ocean model output. Journal of Geophysical Research: Solid Earth, 113, B08410. doi:10.1029/2007JB005338

Tapley, B. D., Bettadpur, S., Ries, J. C., Thompson, P. F., \& Watkins, M. M. (2004). GRACE measurements of mass variability in the Earth system. Science, 305, 503-505.

doi:10.1126/science.1099192

Tregoning, P., Watson, C., Ramillien, G., McQueen, H., \& Zhang, J. (2009). Detecting hydrologic deformation using GRACE and GPS. Geophysical Research Letters, 36, L15401. doi:10.1029/2009GL038718

van Dam, T. (2010). NCEP Derived 6 hourly, global surface displacements at $2.5 \times 2.5$ degree spacing, data set accessed 2018-03-18 at http://geophy.uni.lu/ncep-loading.html.

van Dam, T., Wahr, J., \& Lavallée, D. (2007). A comparison of annual vertical crustal displacements from GPS and Gravity Recovery and Climate Experiment (GRACE) over Europe. Journal of Geophysical Research: Solid Earth, 112, B03404.

doi:10.1029/2006JB004335

van den Broeke, M. R., Enderlin, E. M., Howat, I. M., \& Noël, B. P. (2016). On the recent contribution of the Greenland ice sheet to sea level change. The Cryosphere, 10, 1933-1946. doi:10.5194/tc-10-1933-2016

Velicogna, I., Sutterley, T. C., \& van den Broeke M. R. (2014). Regional acceleration in ice mass loss from Greenland and Antarctica using GRACE time-variable gravity data. Journal of Geophysical Research: Space Physics, 41, 8130-8137. doi:10.1002/2014GL061052 Velicogna, I., \& Wahr, J. (2006). Acceleration of Greenland ice mass loss in spring 2004. Nature, 443, 329-331. doi:10.1038/nature05168

Wahr, J., Molenaar, M., \& Bryan, F. (1998). Time variability of the Earth's gravity field: Hydrological and oceanic effects and their possible detection using GRACE. Journal of Geophysical Research: Solid Earth, 103, 30205-30229. doi:10.1029/98JB02844

Wahr, J., Khan, S. A., van Dam, T., Liu, L., van Angelen, J. H., van den Broeke, M. R., \& Meertens, C. M. (2013). The use of GPS horizontals for loading studies, with applications to northern California and southeast Greenland, Journal of Geophysical Research: Solid Earth, 118, 1795-1806. doi:10.1002/jgrb.50104

Wang, H., Xiang, L., Jia, L., Jiang, L., Wang, Z., Hu, B., \& Gao, P. (2012). Load Love numbers and Green's functions for elastic Earth models PREM, iasp91, ak135, and modified models with refined crustal structure from Crust 2.0. Computers \& geosciences, 49, 190-199. doi:10.1016/j.cageo.2012.06.022

Wang, S. Y., Chen, J. L., Wilson, C. R., Li, J. \& Hu, X. G. (2018). Reconciling GRACE and GPS estimates of long-term load deformation in southern Greenland. Geophysical Journal International, 212, 1302-1313. doi:10.1093/gji/ggx473

Watkins, M. M., Wiese, D. N., Yuan, D. N., Boening, C., \& Landerer, F. W. (2015) Improved methods for observing Earth's time variable mass distribution with GRACE using spherical cap mascons. Journal of Geophysical Research: Solid Earth, 120, 2648-2671, doi:10.1002/2014JB011547

Werth, S., Güntner, A., Schmidt, R., \& Kusche, J. (2009). Evaluation of GRACE filter tools from a hydrological perspective. Geophysical Journal International, 179, 1499-1515. doi:10.1111/j.1365-246X.2009.04355.X

Zhang, L., Dobslaw, H., \& Thomas, M. (2016). Globally gridded terrestrial water storage variations from GRACE satellite gravimetry for hydrometeorological applications. Geophysical Journal International, 206, 368-378. doi:10.1093/gji/ggw153

Zwally, H. J., Li, J., Brenner, A. C., et al. (2011). Greenland ice sheet mass balance: distribution of increased mass loss with climate warming, 2003-07 versus 1992-2002. Journal of Glaciology, 57, 88-102. doi:10.3189/002214311795306682 
Zwally, H. J., Schutz, R., Bentley, C., Bufton, J., Herring, T., Minster, J., Spinhirne, J. \& Thomas, R. (2014). GLAS/ICESat L2 Antarctic and Greenland Ice Sheet Altimetry Data (HDF5), Version 34. NASA National Snow and Ice Data Center Distributed Active Archive Center, Boulder, Colorado USA. doi:10.5067/ICESAT/GLAS/DATA225

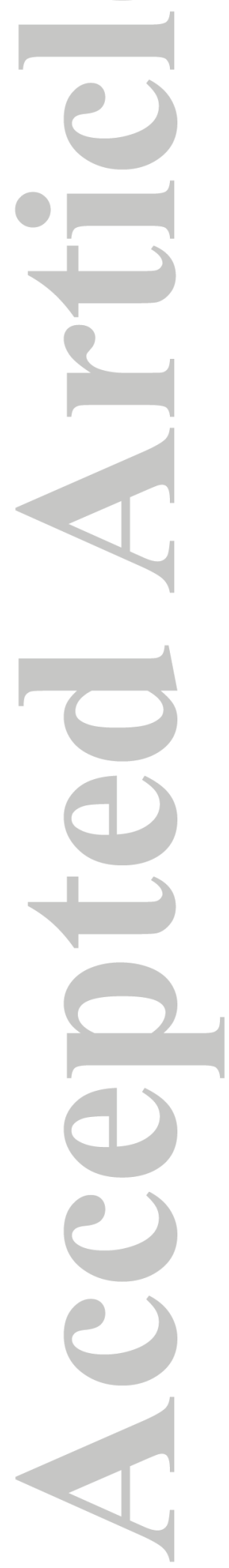


(a) Gris mask and locations of the GNET GPS stations

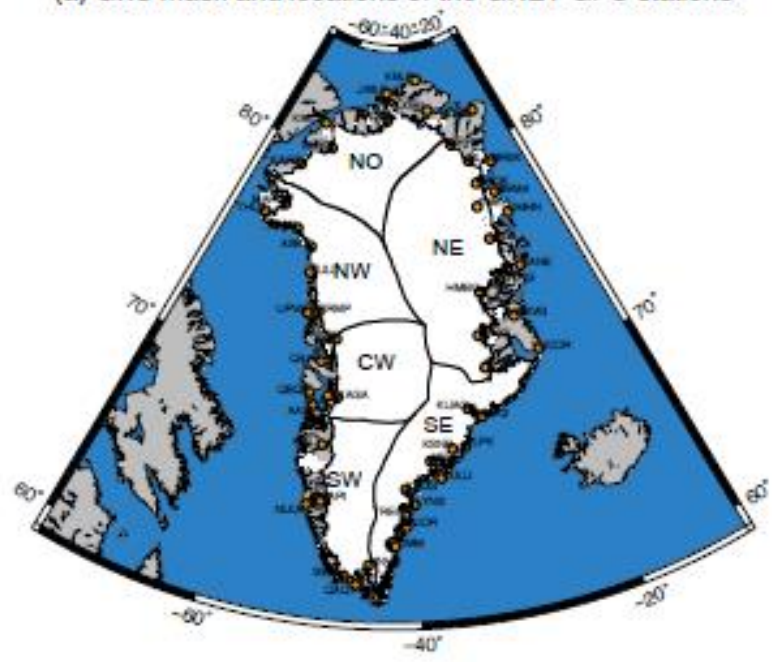

(c) Trend of Accumulated RACMO2.3 SMB Values with $11 \mathrm{~km} \times 11 \mathrm{~km}(2003 \sim 2015)$

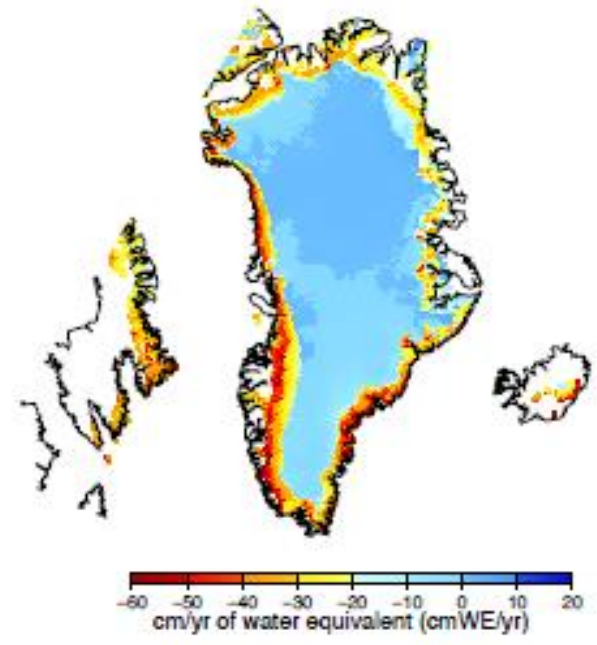

(b) Trend of GrlS mass change from GRACE with Imax $=60(2003 \sim 2015)$

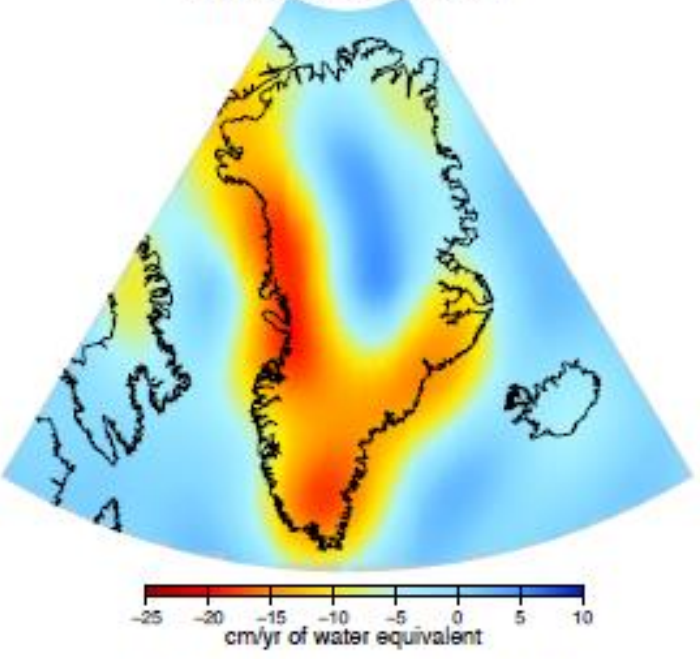

(d) Trend of surface elevation change with $5 \mathrm{~km} \times 5 \mathrm{~km}(2003 \sim 2015)$

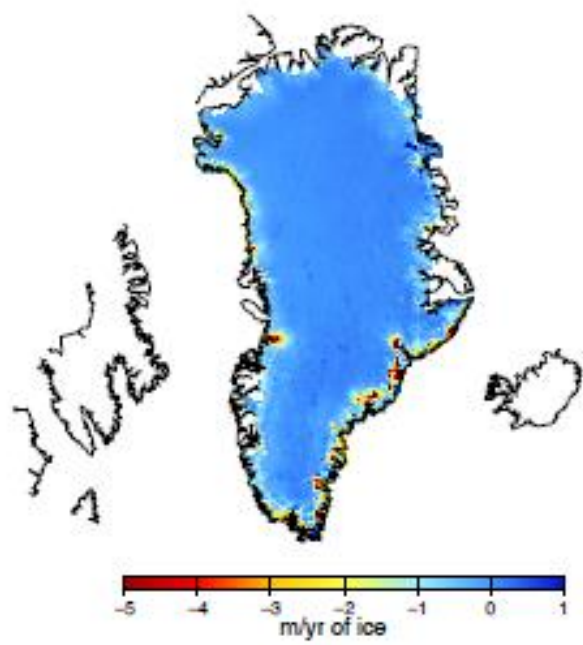

Figure 1. Locations of the GNET stations shown by orange dots (a), GRACE-derived linear trend of the GrIS mass change (b), trend of monthly accumulated surface mass balance (SMB) anomalies (c) and yearly surface elevation change (SEC) (d) from 2003 to 2015. Black curves delineate major drainage basins according Rignot et al. (2011), with six subregions labeled as NE: northeast; NO: north; NW: northwest; CW: central west; $\mathrm{SW}$ : southwest and SE: southeast. 


\section{GPS-observed and GRACE-derived long-term uplift rates}

time span of the data analyzed is from 2003 to 2015

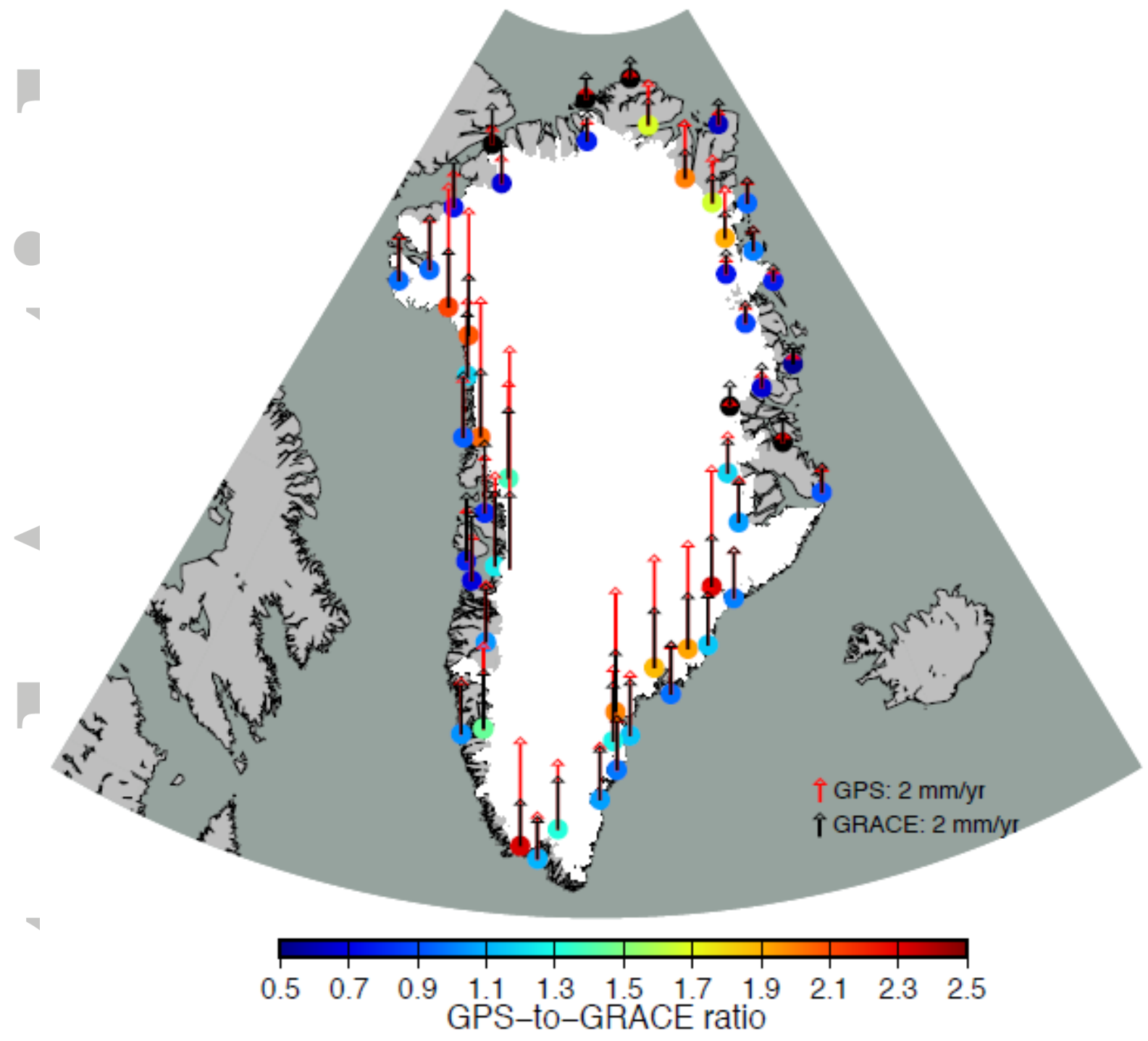

Figure 2. GPS observed (red arrows) and GRACE predicted (gray arrows) vertical velocities (after removing the atmospheric, non-tidal oceanic loading and GIA effects) for GNET stations in Greenland. The color dots show GPS-to-GRACE ratios. The time span of GRACE date was 2003 to 2015 and for the selected time span of the GPS date please see Table S1 in Supporting Information.

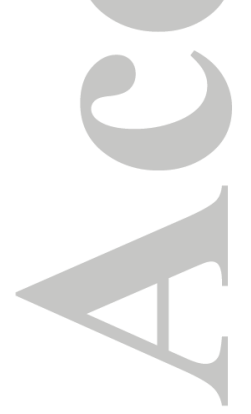


(a) Weighted SEC and SMB scaling factors for ice mass with 0.5 grids

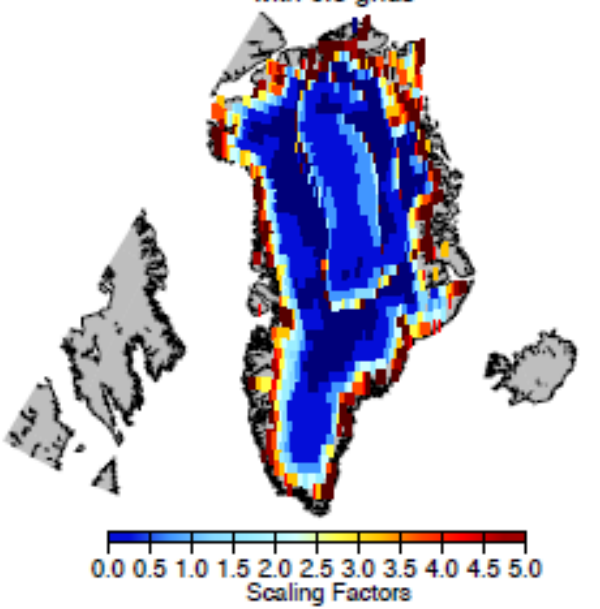

(b) Weighted_SEC_SMB scaled GrIS mass trend

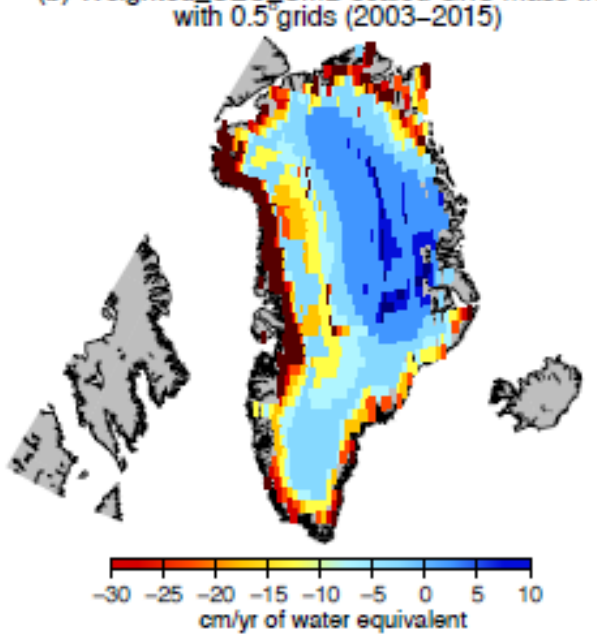

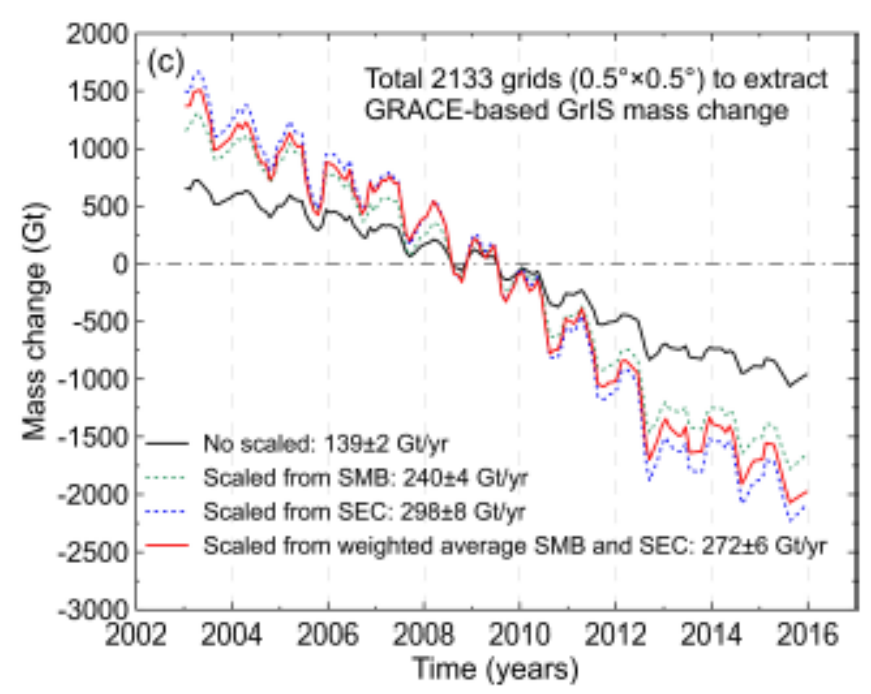

Figure 3. Time series of GrIS changes for unscaled and scaled (SMB, SEC and mean) GRACE data. The errors represent fitting uncertainties (i.e., root-mean-square error), while real uncertainties come chiefly from the GRACE measurement errors, leakage of the signal from outside the ice sheet, and GIA correction. Gridded scaling factors for mass changes computed for SMB and SEC are shown in Figure S3 in the Supporting materials. 


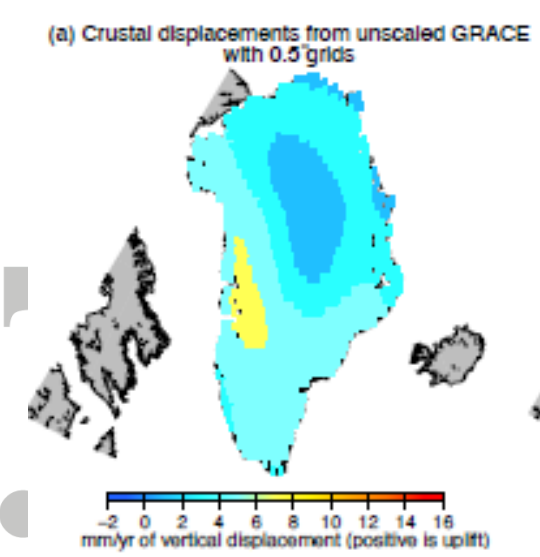

(b) Weighted SEC and SMB scallng factors for crustal uplift with 0.5 grilis
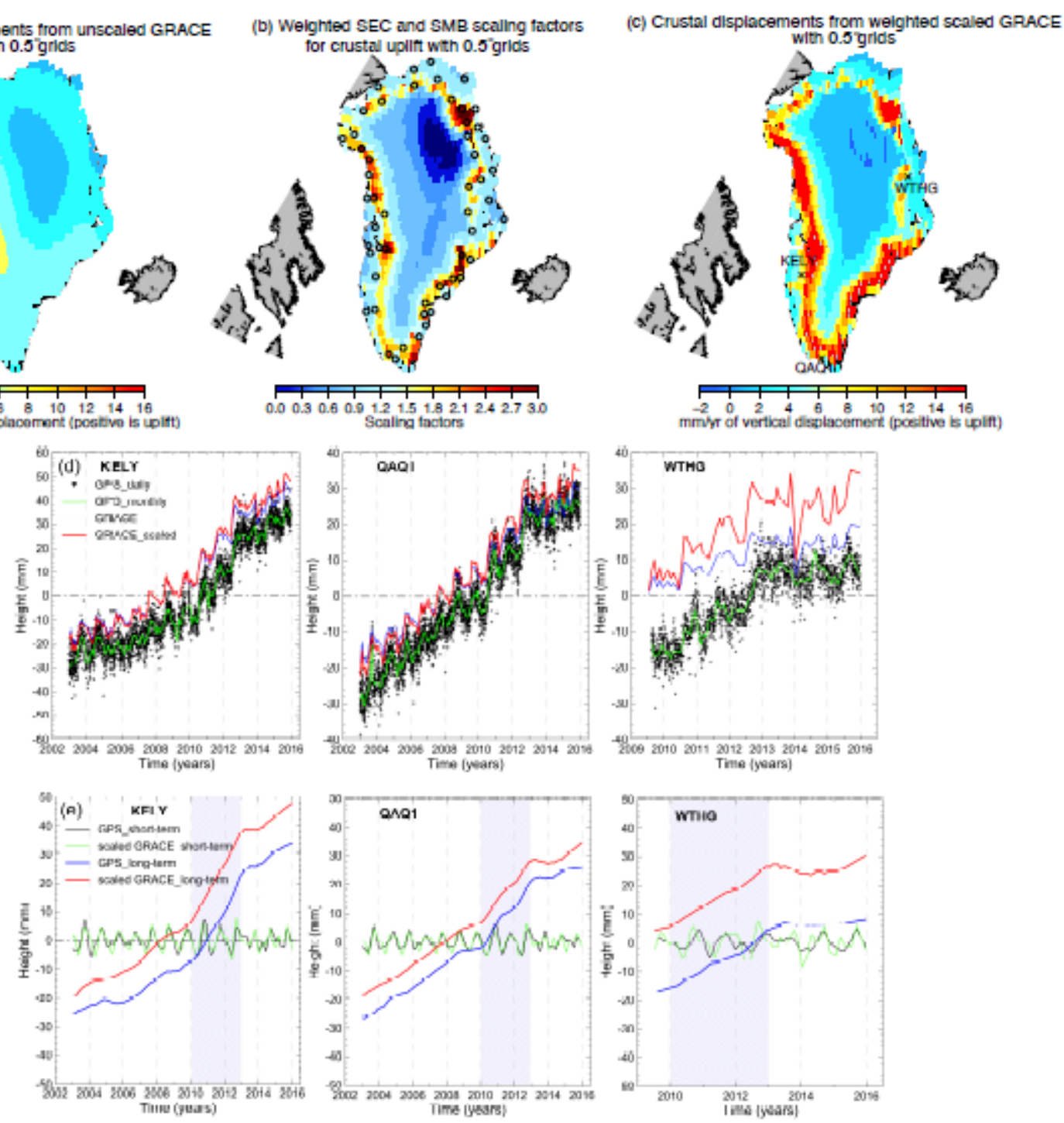

Figure 4. Downscaled GRACE-based predictions of vertical displacements in Greenland and comparisons with GPS observations. (a) Weighted scaling factors at the $0.5^{\circ}$ resolution derived from SMB and SEC model-predicted vertical displacement changes. (b) Unscaled GRACE prediction of uplift (in mm/yr). (c) Downscaled GRACE prediction of uplift (in $\mathrm{mm} / \mathrm{yr}$ ). (d) Comparisons of daily and monthly GPS heights, unscaled and scaled GRACE predicted yertical displacements using the weighted scaling factors at the KELY, QAQ1 and WTHG site, which locations are shown in (c). (e) GPS-observed and scaled GRACE-derived the short-term and long-term vertical displacement time series for the same GPS locations as shown in Figure 4c. Atmospheric, non-tidal oceanic loading and GIA effects were removed from GPS and GRACE data. 
WRMS reduction of GPS after removing scaled GRACE-derived vertical displacements at GNET

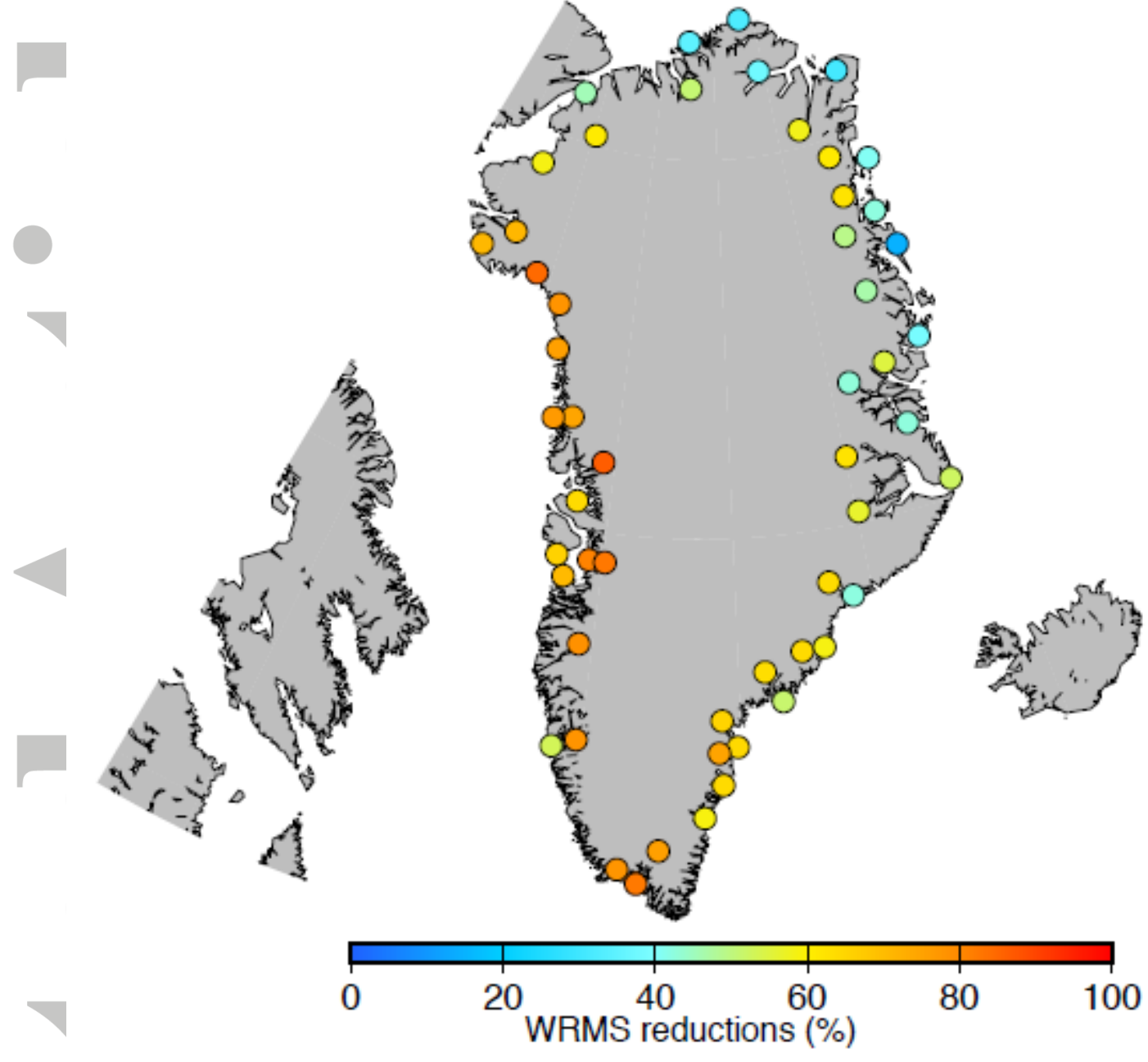

Figure 5. WRMS reductions for GPS-observed vertical displacements after removing scaled GRACE-derived results at GNET sites. 

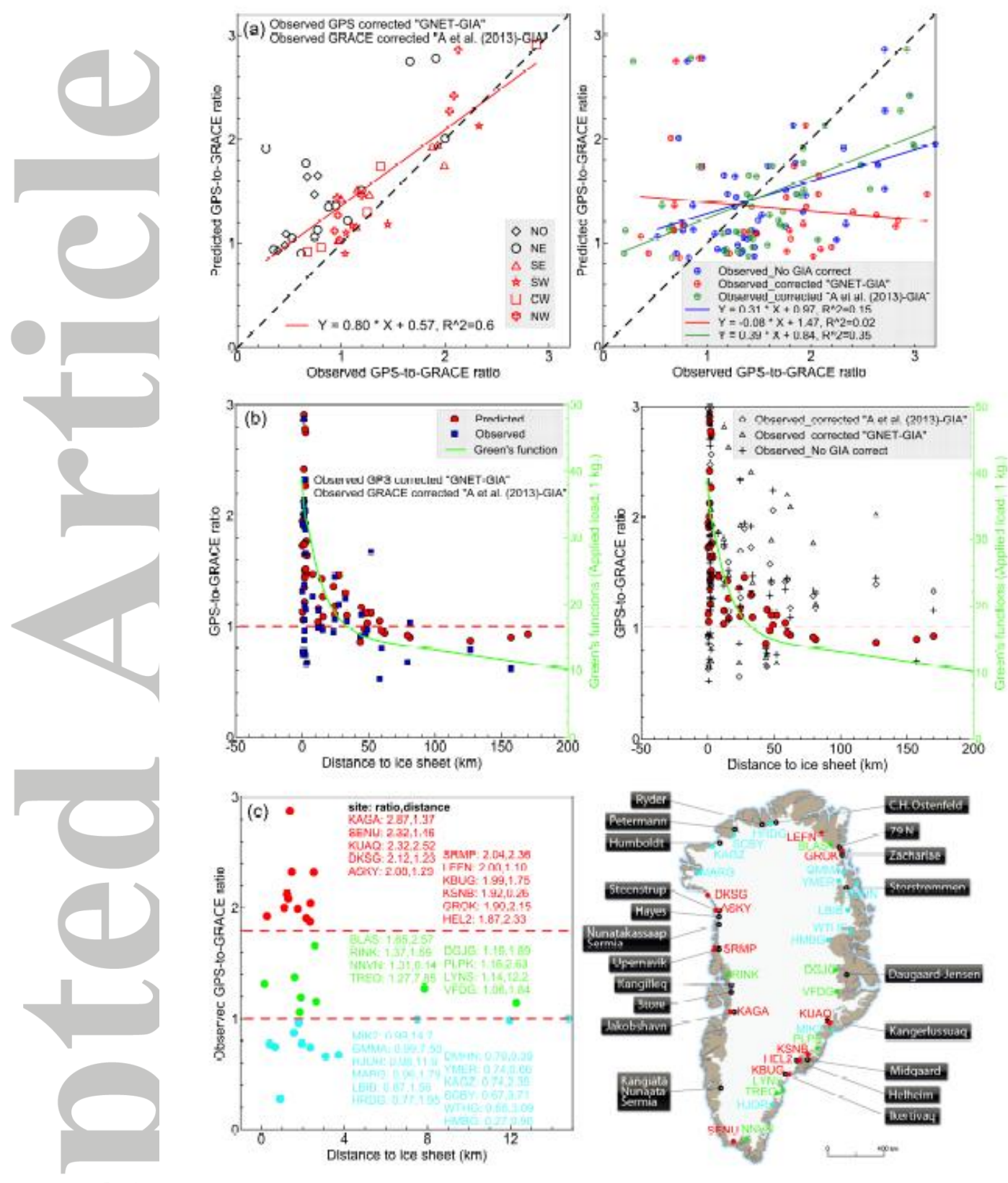

Figure 6. Predicted GPS-to-GRACE ratios versus observed ratios at GNET sites (a) and the relationship between GPS-to-GRACE ratios and distance from GPS sites to the margins of GrIS (b). Green curve in (b) is the vertical Green's function (i.e., radial displacement multiplied by factor of $10^{12} \times[\mathrm{R} \times$ theta], unit is $\mathrm{cm}, \mathrm{R}$ is the radius of the Earth and theta is angular distance from the load in radians) for the model PREM/Continental crust for a distance range of 0-200 km introduced by Jentzsch (1997). (c) Observed GPS-to-GRACE ratios for the stations close to the ice margin for a distance range of $0-15 \mathrm{~km}$. Different colors of the stations represent different types of the ice marginal zones. Black dots show glacier front positions at twenty major outlet glaciers (POLAR PORTAL, available at http://polarportal.dk/en/greenland/glacier-front-positions/). 


\section{Vertical displacement Green's function at GNET \\ Exact \\ $\operatorname{Lmax}=60$}

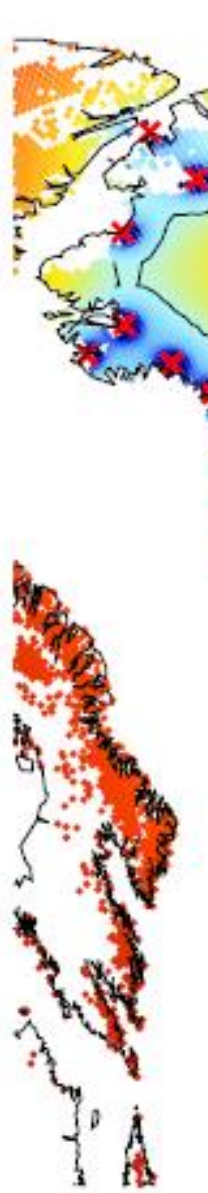

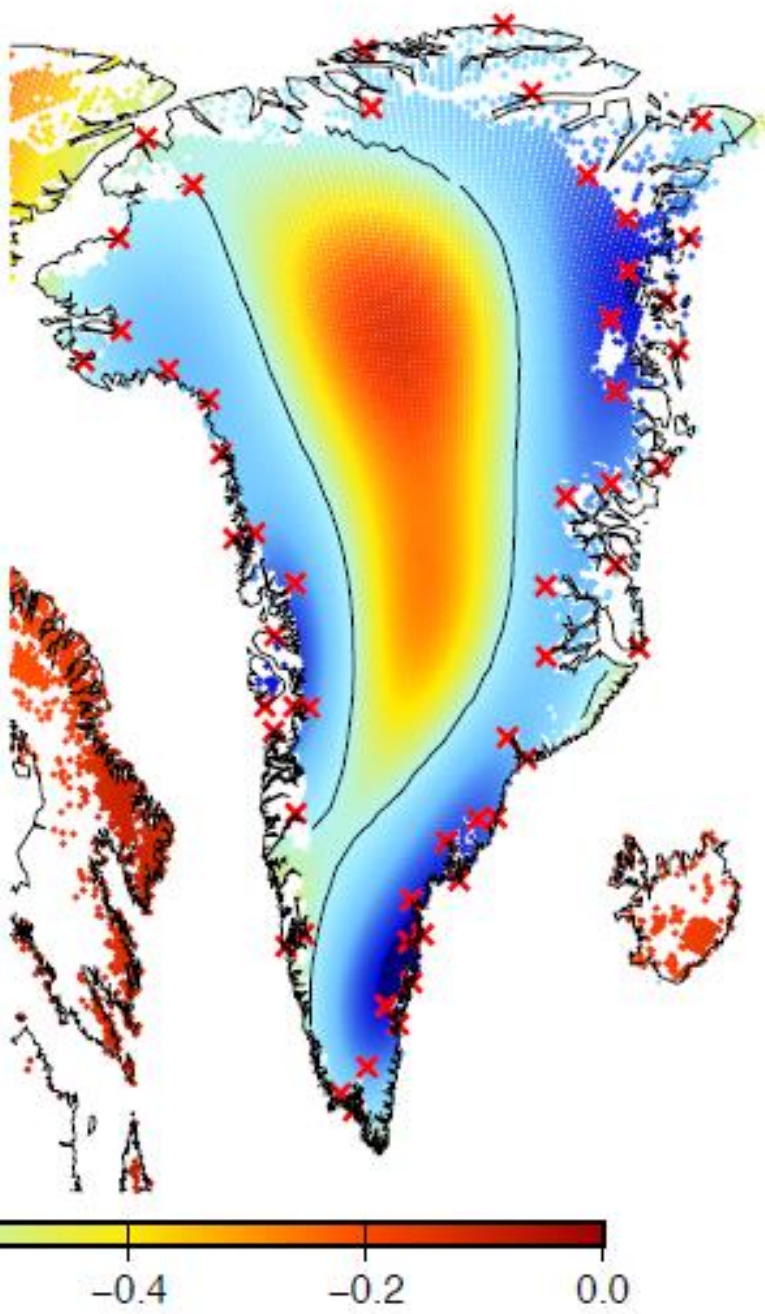

Figure 7. The sum of vertical displacement Green's function (i.e., radial displacement multiplied by factor of $10^{12} \times$ [R $\times$ theta], unit is $\mathrm{cm}$ ) for GNET at each GrIS mask grid point $\left(0.5^{\circ}\right.$ grids) for the upper limit $l_{\max }=\infty$ (exact) and $l_{\max }=60$ (truncation). The black curve represents the mean value of the loading Green's functions for all stations. 


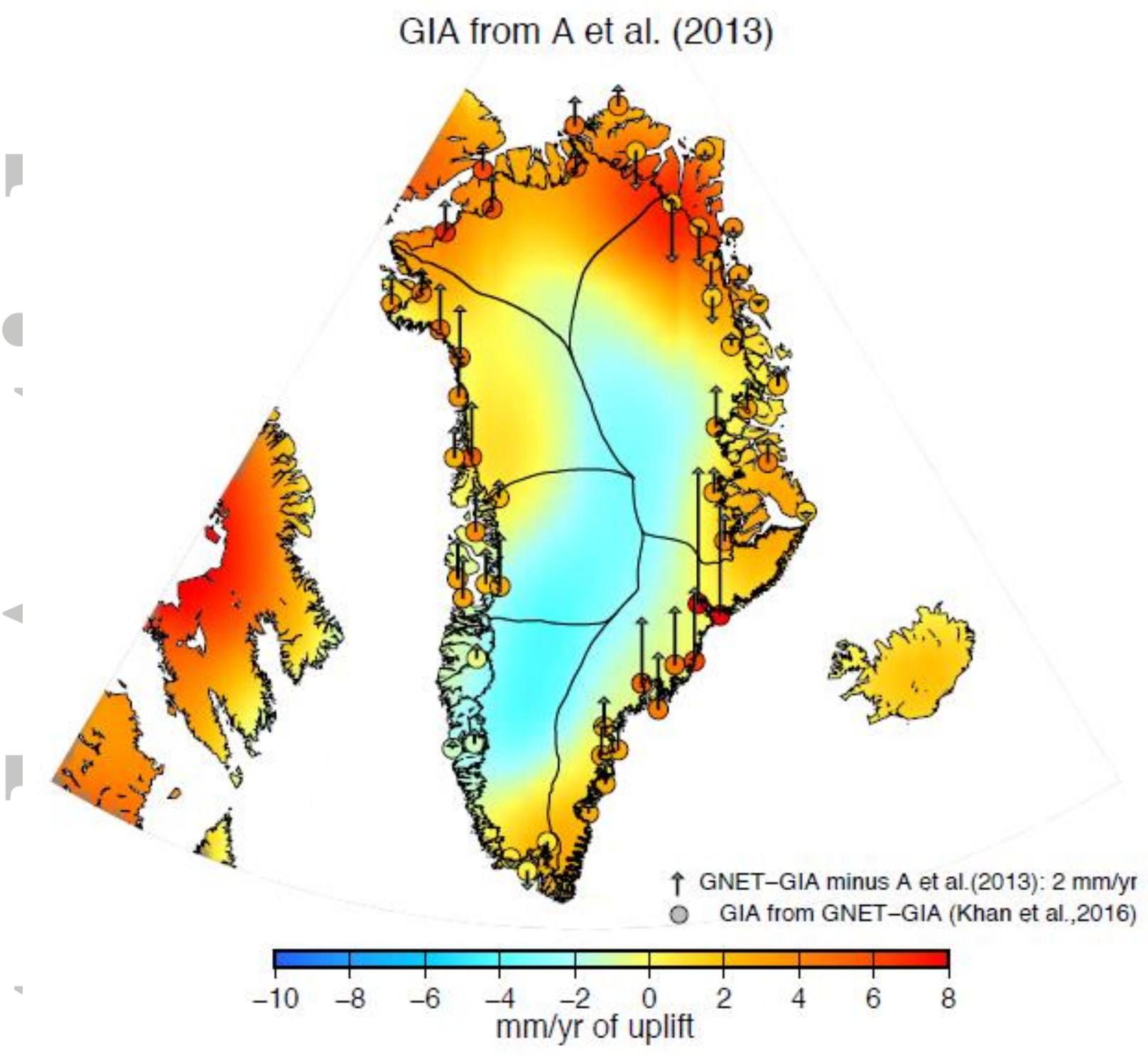

Figure 8. GIA vertical displacement rates from the model of A et al. (2013) for Greenland and "GNET-GIA" model for GNET sites (dots). Grey arrows represent differences between "GNET-GIA" and the model of A et al. (2013). 